\title{
Temperature Flows in Railway Tunnels: Field Measurements of Frost Penetration
}

\author{
Anna Andrén', Lars-Olof Dahlström ${ }^{2}$ and Erling Nordlund ${ }^{3}$
}

\begin{abstract}
Even though extensive pre-grouting is carried out during the construction of tunnels, certain leakages and drips remain. These remaining leakages are remedied by a combination of post-injection and drainage measures with, for example, frost insulated drain mats, whose function is to prevent the cold tunnel air from reaching a leakage spot and causing water to freeze. Despite these measures, some water may still enter the tunnels and cause problems during winter with ice formations and frost shattering. Icicles, ice pillars and ice-covered roads and railway tracks require constant maintenance. If ice occurs in the fracture network close to the tunnel contour or in the interface between the rock and shotcrete, it can cause degradation of the load-bearing capacity of the tunnel and fall-outs of both materials. In tunnel sections with water leakage problems it is common to protect the load-bearing structure from freezing with insulated drainage systems. To determine where along the tunnel efforts must be made to prevent ice formation, the temperature conditions of tunnels must be investigated. This article presents parts of the results from field measurements in two Swedish railway tunnels. The measurements involves monitoring of air and rock temperatures, air pressure and air velocity.
\end{abstract}

Keywords: Frost penetration, ice formation, frost shattering, temperature measurement, maintenance, railway tunnel.

1 The Swedish Transport Administration, Borlänge, Sweden.

2 Adjunct Professor, Department of Civil, Environmental and Natural Resources Engineering, Luleå University of Technology, Luleå, Sweden.

${ }^{3}$ Chaired Professor, Department of Civil, Environmental and Natural Resources Engineering, Luleå University of Technology, Luleå, Sweden.

Article Info: Received: November 3, 2020. Revised: November 22, 2020.

Published online: November 25, 2020. 


\section{Introduction and background}

Frost penetration along tunnels with leaking water and its consequence for the degradation of railway and road tunnels is a major problem in cold regions such as Sweden. This article focuses its attention on railway tunnels. During the winter, ice causes major problems in several of the Swedish Transport Administration's railway tunnels. In order to maintain operation and safe passages, continuous maintenance has to be performed during the winter. Freezing water forms icicles and pillars that, if not removed, can fall down and damage both installations and passing vehicles. Sometimes the ice formations grow so large that they encroach the gauge clearance and operational space of the tunnel. Equipment and cables can fail because of the weight of the ice and tracks may become covered with ice (Figure 1). Periodic freezing can cause frost shattering and this process can cause fall-outs of rock and shotcrete [1]. In order to maintain safety and prevent traffic disruption, many tunnels require extensive maintenance. In order to reduce maintenance of the tunnels, improved knowledge and understanding of the temperature flow, frost penetration and the effects of ice pressure and consequently the disintegration of the load-bearing structure and its capacity is required. Better knowledge allows new designs and coordinated maintenance programs to be developed.

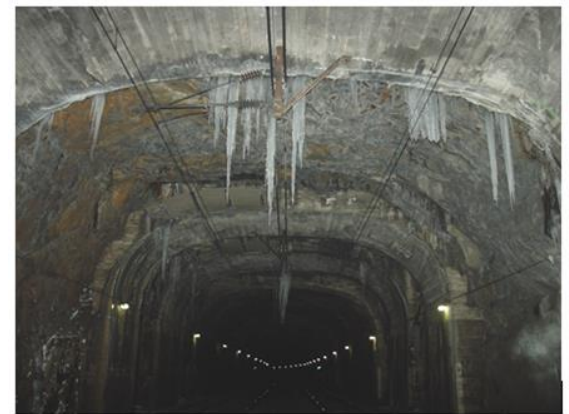

a)

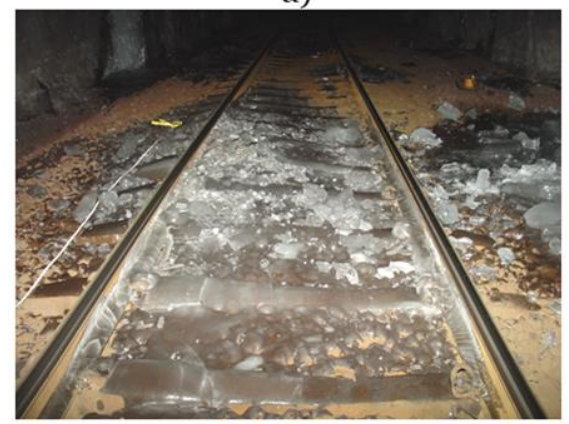

b)

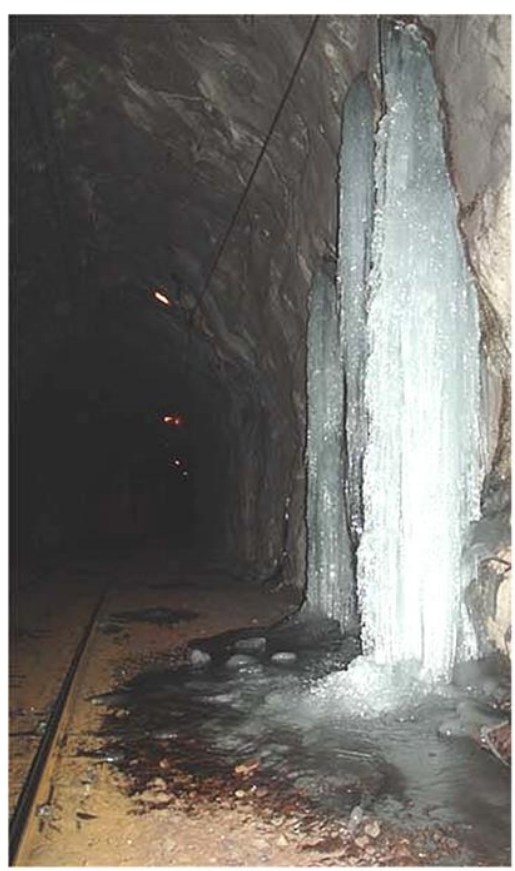

c)

Figure 1: Typical ice formation problems that may develop in unlined tunnels:

a) Icicles in the tunnel roof

b) Ice layer spread out over the tunnel floor

c) Ice pillars or icefall on the tunnel wall [2]. 
The University of Gävle and the Royal Institute of Technology, Stockholm [3] carried out a laboratory model test on behalf of the Swedish National Rail Administration (now the Swedish Transport Administration). The objective of the model test was to find a method for determining the expected tunnel temperature conditions along a tunnel and to provide information to be used to decide which parts of the tunnel that require frost insulation to protect the drainage system from freezing and prevent ice formation. Sandberg et al. [3] concluded that the predominant cause of frost penetration is the thermally-induced air flow, due to differences in outside air temperature and tunnel air temperature, as well as the inclination of the tunnel. The air flow rises because the cold outside air is heated by the warm rock mass in the tunnel. The heated tunnel air moves, due to the convection or chimney effect, towards the higher tunnel entrance. The greater the thermal difference of outside air versus tunnel air temperature, and the greater the elevation difference of the tunnel entrances, the greater the chimney effect. To verify the model test, field measurements were performed in collaboration between the Swedish Transport Administration and Luleå University of Technology [4]. Verification involved monitoring of temperatures in air, rock surfaces and in rock mass at different locations along two railway tunnels. Parallel to the temperature measurements, air velocities and air pressures were monitored.

One difference between the model test and the field measurements is that the model test theories are based on a completely uninsulated tunnel. The tunnels in this field test have a lot of insulated drain mats installed. However, the insulation does not only prevent the cold air from reaching the leakage spots, but also prevents the heat from the rock mass from entering the tunnel and warming up the cold tunnel air. Consequently, the freezing temperatures move further into the tunnel than they would if the heat from the rock mass was allowed to warm up the outside air on its way into the tunnel [1]. In an investigation conducted in 2004-2005 by Andrén, recurring inspections of ice and water problems in five railway tunnels showed that when the cold outside air is able to penetrate further into the tunnel, the frost problems in the inner parts will increase. Ice problems occur not only around the entrances, but also often along the entire length of the tunnel. In early winter, the ice problems are most apparent close to the entrances, and tend to move inward the tunnel as winter goes on. When the rock mass has finally frozen in a specific section of the tunnel, water in the fractures freezes and stops further water leakage into the tunnel [2]. 


\section{Field study}

Two tunnels in different climate zones were selected for the field study; the Åsa tunnel located in the south of Sweden and the Glödberget tunnel in the northern part of Sweden. The Åsa tunnel has a low point, about two thirds into the tunnel from the north, while the Glödberget tunnel has a constant inclination from south down towards north.

To specify where along the tunnel different measuring stations are located, an expression for length measurement will be used. The term "chainage km $20+100$ " means that the measuring length is $20 \mathrm{~km}$ and $100 \mathrm{~m}$ from a specified zero point. The zero point for the Åsa tunnel is in Gothenburg and for the Glödberget tunnel, the zero point lies in Stockholm.

\subsection{The Åsa tunnel}

The Åsa tunnel is a double-track tunnel with a length of $1850 \mathrm{~m}$. It is located $50 \mathrm{~km}$ south of Gothenburg (Figure 2). The northern entrance is located at chainage km $46+451$ and the southern entrance is located at chainage $\mathrm{km} \mathrm{48+300.} \mathrm{The} \mathrm{tunnel}$ declines approximately $10 \%$ from the northern entrance towards its lowest point at chainage $\mathrm{km} 47+490$ and then inclines $12 \%$ towards the southern entrance. The elevation difference between the higher north and the lower south entrance is only about 1 meter, but the low point further into the tunnel $(1039 \mathrm{~m}$ in the tunnel from north) is approximately $7 \mathrm{~m}$ lower than the northern entrance and $6 \mathrm{~m}$ lower than the southern entrance (Figure 3). The tunnel height is $7.3 \mathrm{~m}$ above the top of rail and the width is $14 \mathrm{~m}$. The rock type in the area is intrusive granite and granodiorite with gneissic texture and the tunnel is reinforced with selective bolting and shotcrete with a thickness of $40 \mathrm{~mm}$ in the roof in most sections along the tunnel. In some sections, the roof is supported with bolts and shotcrete with a thickness of $70 \mathrm{~mm}$. In some parts of the tunnel where more extensive water leakage occurs, insulated drain mats have been installed to protect installations from dripping water and to prevent freezing. 

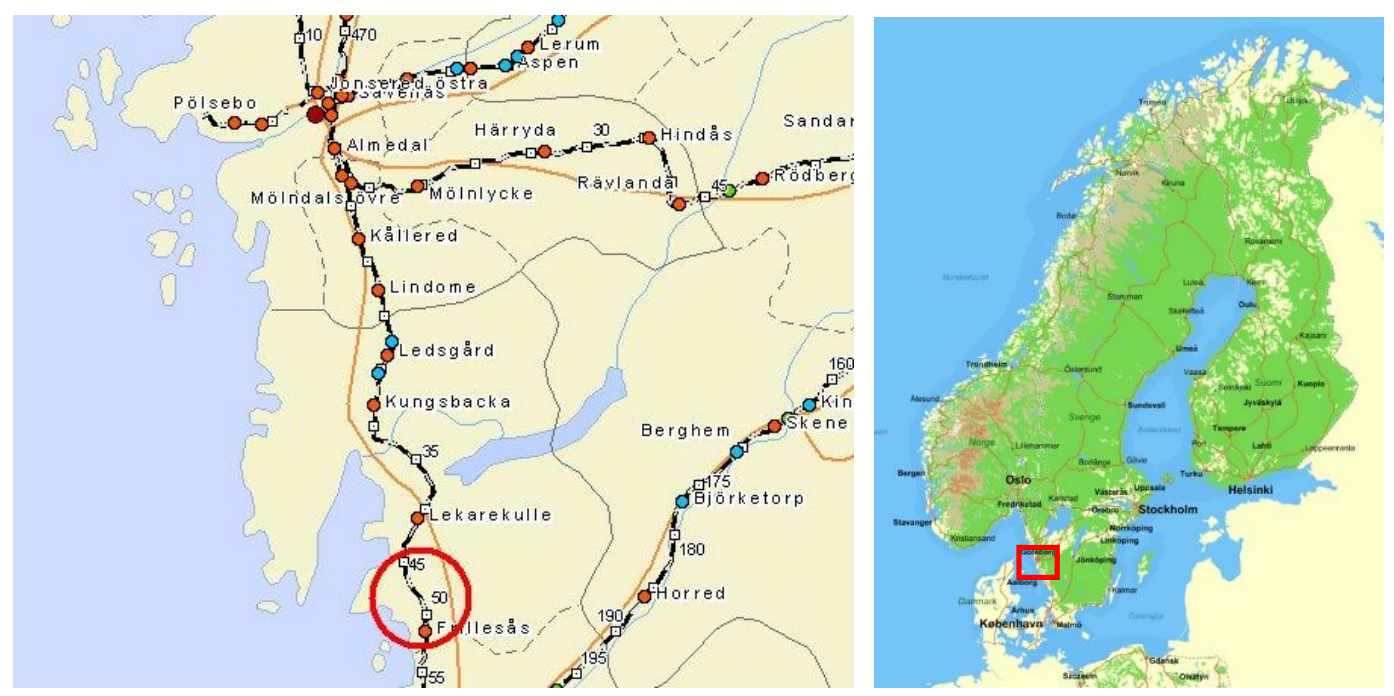

Figure 2: Map of the location of the Åsa tunnel.

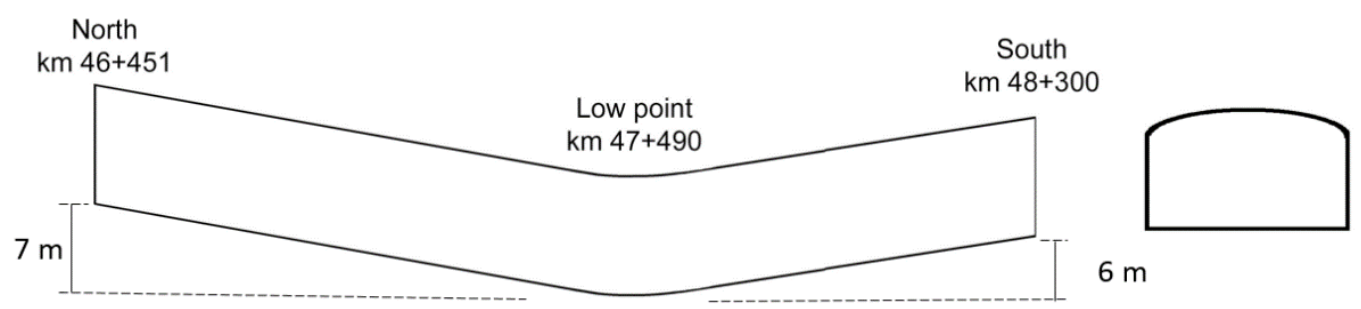

Figure 3: Longitudinal sketch of the Åsa tunnel.

\subsection{The Glödberget tunnel}

The Glödberget tunnel is a single-track tunnel, $1680 \mathrm{~m}$ long, near Nyåker, 80 km southwest of Umeå (Figure 4). The southern entrance is located at chainage km $816+160$ and the northern entrance at chainage $\mathrm{km} 817+840$. The tunnel has, unlike the Åsa tunnel, a constant inclination of $12.5 \%$. The elevation difference between the higher south entrance and the lower north entrance is $21 \mathrm{~m}$ (Figure 5). The tunnel consists from the south of a $60 \mathrm{~m}$ long concrete tunnel between chainage $\mathrm{km}$ $816+160$ and chainage $\mathrm{km} 816+220$, before entering into the $1350 \mathrm{~m}$ long rock tunnel. The rock tunnel is reinforced with bolts and shotcrete (thickness: roof 60 $\mathrm{mm}$ and wall $25 \mathrm{~mm}$ in most sections along the tunnel) until chainage $\mathrm{km} 817+570$. In the north, the tunnel ends with a $270 \mathrm{~m}$ long concrete tunnel between chainage $\mathrm{km} 817+570$ and chainage $\mathrm{km} 817+840$. The tunnel height is $7 \mathrm{~m}$ above the top of rail and the width is $8 \mathrm{~m}$. The rock type in the area is intrusive granite, metagreywacke and granodiorite. The insulated drain mats installed in the Glödberget tunnel are twice as thick as those installed in the Åsa tunnel, due to a more sever climate zone. A total of $70 \%$ of the roof and the walls are covered with drain mats with a thickness of $140 \mathrm{~mm}$. The insulated drain mats along the $1680 \mathrm{~m}$ 
long tunnel are distributed as follows: southern third $20 \%$, middle third $48 \%$ and northern third $2 \%$.
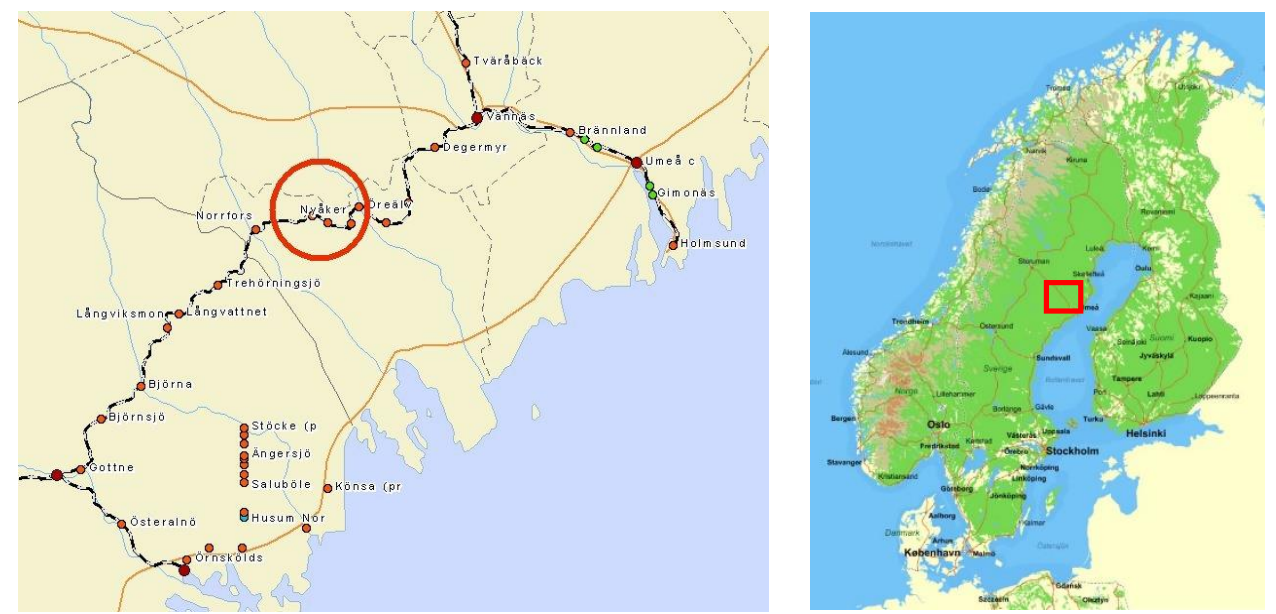

Figure 4: Map of the location of the Glödberget tunnel.

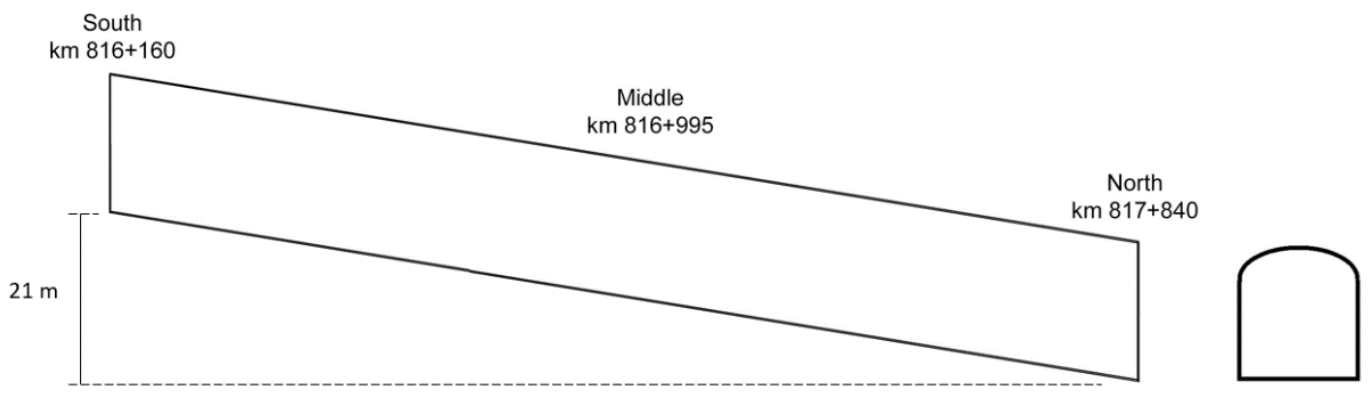

Figure 5: Longitudinal sketch of the Glödberget tunnel.

\subsection{Field test configuration}

The first monitoring system was installed in the Åsa tunnel in April 2006, and a second system was installed in the Glödberget tunnel, in February 2007. Both systems measure air and rock surface temperatures at nine sections along the tunnels. In addition to this, air pressures were measured in two sections, air velocity in three sections, and the rock mass temperatures were measured at $10 \mathrm{~cm}$ depths from the tunnel wall surface in five sections in the Åsa tunnel and at two depths, $10 \mathrm{~cm}$ and $50 \mathrm{~cm}$ from the tunnel wall surface, in four sections in the Glödberget tunnel. In the Glödberget tunnel, the temperature was also measured in the ballast bed, behind an insulated drain mat and in the adjacent service tunnel. The service tunnel runs partially parallel to the track tunnel. The outline of the monitoring system installed in the Âsa tunnel can be seen in Figure 6 and for the Glödberget tunnel in Figure 7. The temperature sensors, model "Termistor 107B" and the logger model "CR10X" are both from Campbell Scientific, whereas the instruments for wind and air velocity, wind direction and digital barometer are developed by Vaisala. The router 
that allows communication with the measuring stations is a CISCO router 2811 Dc manufactured by CISCO. The logger system stores data every ten minutes.

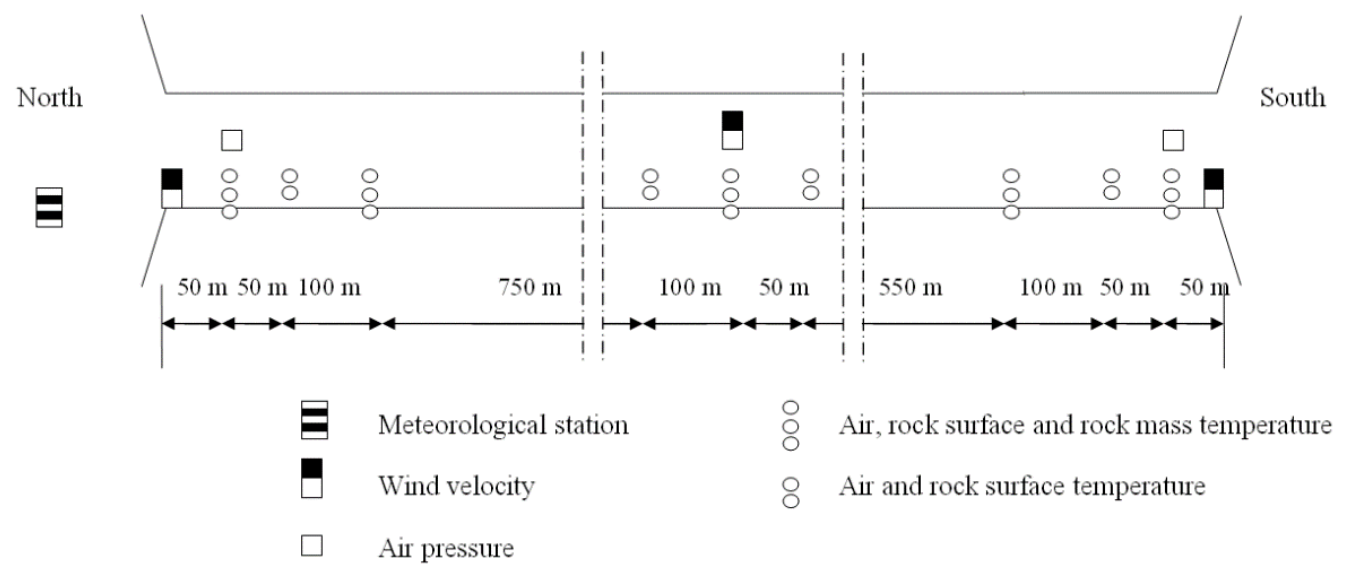

Figure 6: Configuration and outline of the monitoring system installed in the Åsa tunnel.

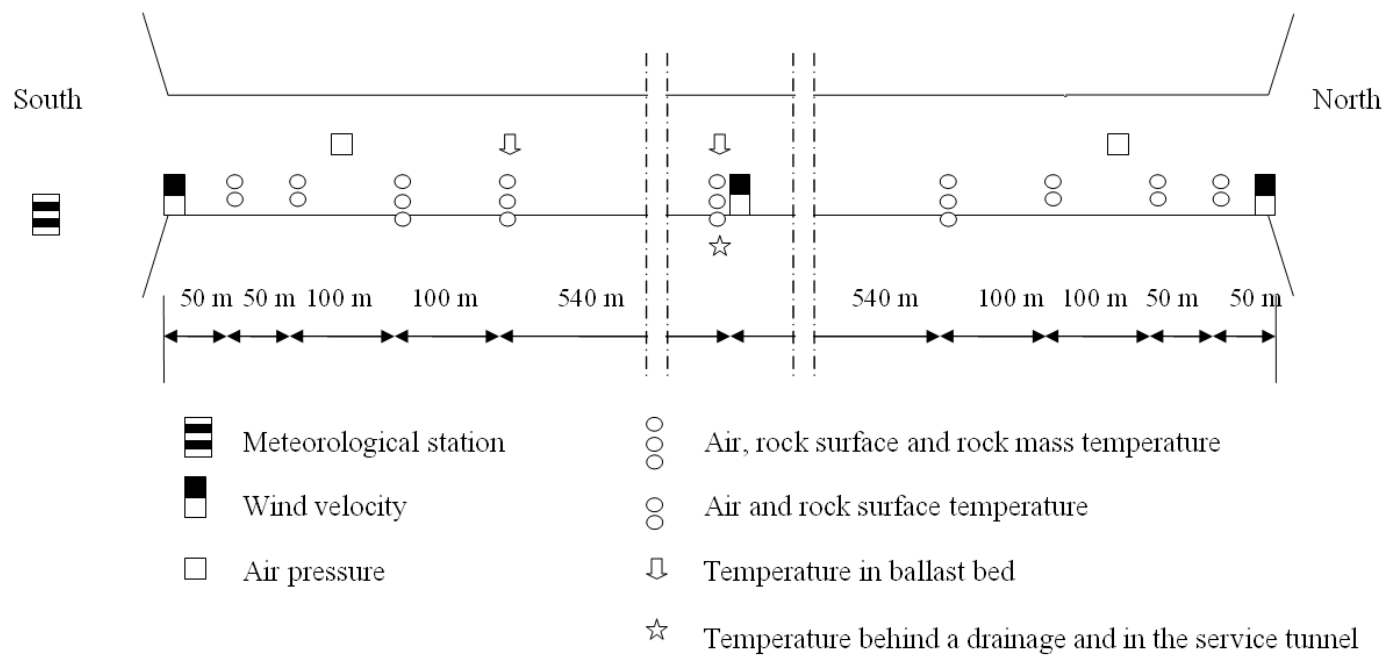

Figure 7: Configuration and outline of the monitoring system installed in the Glödberget tunnel.

\subsubsection{Installation of meteorological stations}

Meteorological stations were installed outside the highest tunnel entrance for both tunnels, to get the outside temperatures, which are compared with temperatures in the tunnels. Wind velocity and wind direction were measured at the top of the mast, which is located $10 \mathrm{~m}$ above the ground surface. Air temperature and atmospheric humidity were measured about $1.5 \mathrm{~m}$ above the ground level and the equipment has a radiation protection that protects against direct sunlight and rainfall (Figure 8). 


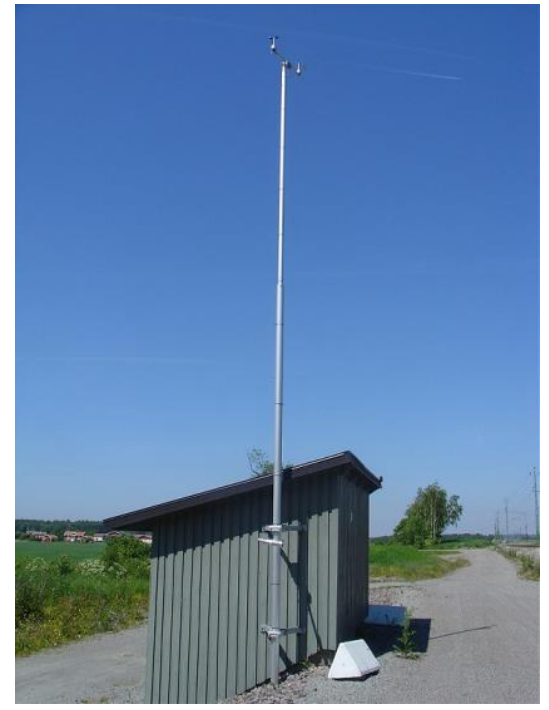

a)

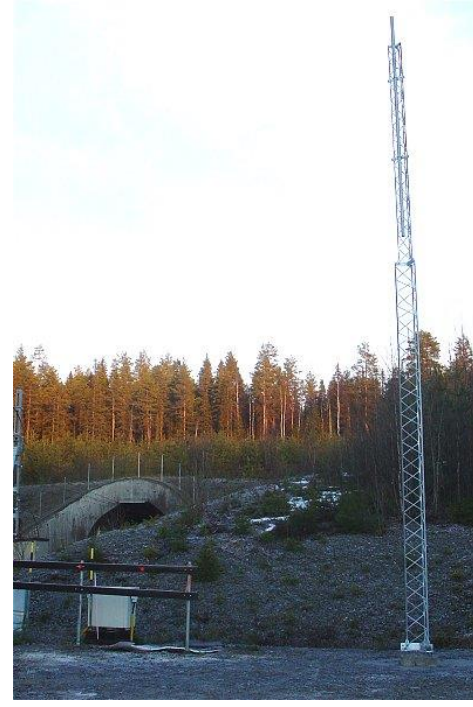

b)

Figure 8: Mast for meteorological station at:

a) the northern entrance of the Åsa tunnel b) the southern entrance of the Glödberget tunnel.

\subsubsection{Installation of temperature sensors in the track tunnels}

Measurements of temperatures of the tunnel air and the rock surface have been made to analyze the frost penetration along the tunnel. Furthermore, the measurements in the rock mass perpendicular to the tunnel wall, were performed to monitor how the freezing front propagates depending on the tunnel air temperature. The air temperature sensors in the track tunnels were installed at the handrail, approximately $10-20 \mathrm{~cm}$ from the tunnel wall surface and $1.2 \mathrm{~m}$ above the surface of the sidewalk. The rock surface temperature sensors were installed in contact with the rock/shotcrete and covered with insulating material as not to be affected by the temperature of the tunnel air. The rock mass temperature sensors were placed in boreholes, which were filled up with insulating material to prevent convection, to allow the gauges to measure true rock mass temperature (Figure 9 and Figure 10). 


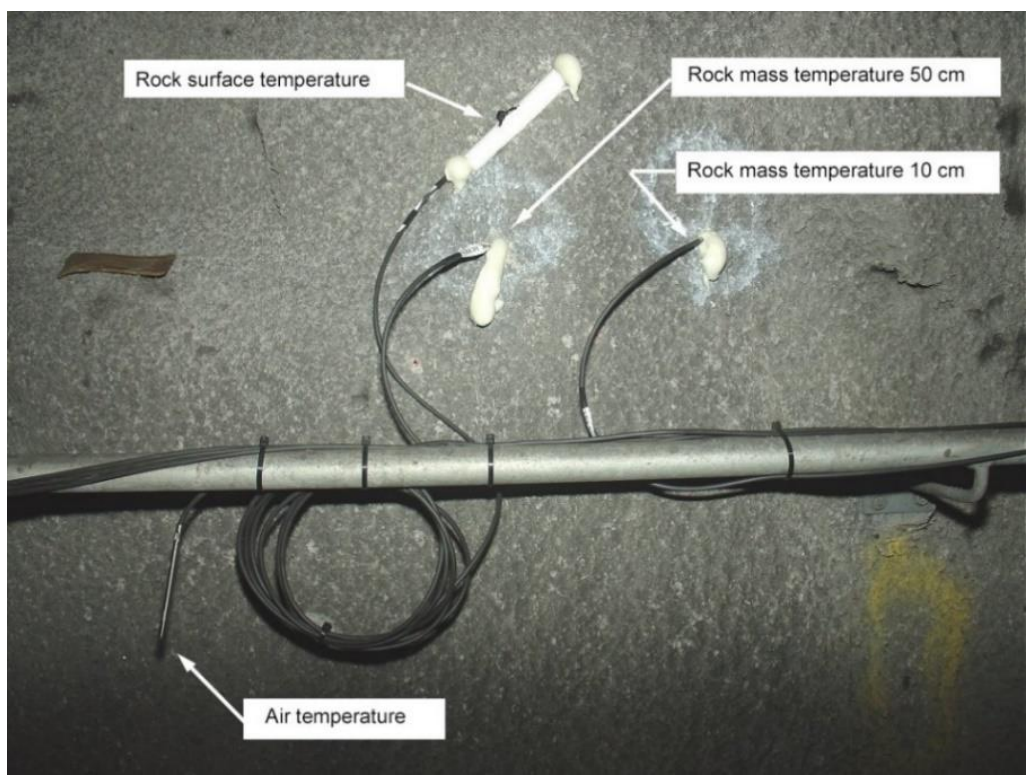

Figure 9: Temperature sensor at a typical measuring station.

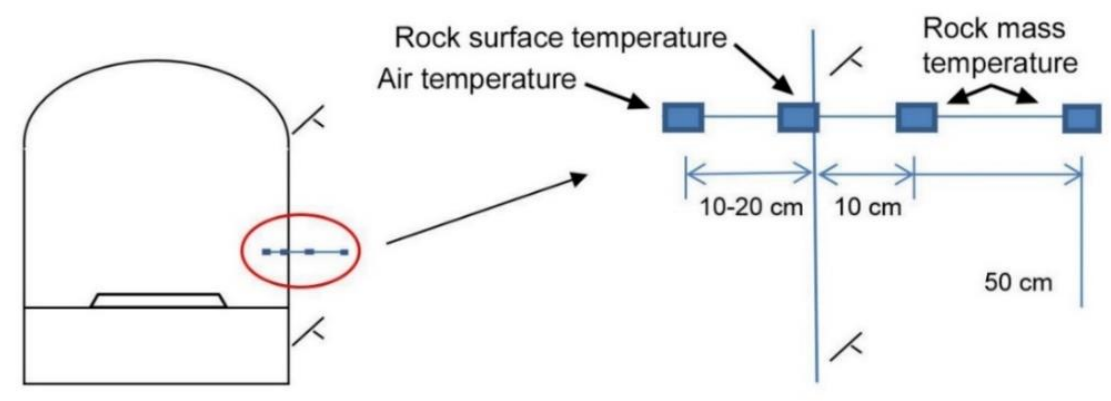

Figure 10: Location of temperature sensors. In the Glödberget tunnel, the rock mass temperatures were measured at the depths of 10 and $50 \mathrm{~cm}$, and in the Åsa tunnel only at a depth of $10 \mathrm{~cm}$.

\subsubsection{Installation of temperature sensors behind a frost insulated drain mat in the Glödberget tunnel}

The frost insulated drain mat at chainage $\mathrm{km} 816+990$ in the middle of the Glödberget tunnel consists of double polyethylene mats and has a total thickness of $140 \mathrm{~mm}$. The drain is sprayed with three layers of shotcrete with a total thickness of $80 \mathrm{~mm}$. The temperature sensor was installed behind the drain mat, approximately $1.2 \mathrm{~m}$ above the surface of the sidewalk. The purpose of the measurement, is to monitor temperature differences between the tunnel air and the air behind a drain mat, heated by the rock mass, in order to determine the effect of the insulation and verify the design. 


\subsubsection{Installation of temperature sensors in the adjacent service tunnel in the Glödberget tunnel}

In the middle of the track tunnel in Glödberget (at chainage km 816+960) there is an entrance to the adjacent service tunnel. About $10 \mathrm{~m}$ into the service tunnel from the track tunnel door, sensors for air and rock surface temperatures were installed approximately $1.2 \mathrm{~m}$ above the surface of the tunnel floor. The cause of the measurements in the adjacent service tunnel is to improve knowledge about the influence of air movements for the tunnel air temperature. The service tunnel has closed doors, both towards the track tunnel and to the outside air, so the air motion is constrained as opposed to the air motion in the track tunnel.

\subsubsection{Installation of temperature sensors in ballast bed in the Glödberget tunnel}

In accordance with the applicable regulations in year 1995 (when the Glödberget tunnel was built), the Swedish regulations [5] require that drainage pipes and drainage water in the ground, if not insulated, must be installed at frost-proof depth to eliminate freezing of the drainage water. Due to the location of the Glödberget tunnel, the requirement for frost-free depth in the ground was $2 \mathrm{~m}$. The same rules applied to frost-free depth inside the tunnel. To investigate the relevance of this requirement of $2 \mathrm{~m}$ depth of the ballast bed, measurements have been made at two sections in the Glödberget tunnel. The first measuring station were placed $300 \mathrm{~m}$ from the south entrance $(\mathrm{km} \mathrm{816+460)}$ and the second in the middle of the tunnel ( $\mathrm{km} \mathrm{816+995).} \mathrm{The} \mathrm{sensors} \mathrm{were} \mathrm{placed} \mathrm{down} \mathrm{in} \mathrm{the} \mathrm{ballast} \mathrm{bed,} \mathrm{under} \mathrm{the} \mathrm{rail}$ construction, at depth of $0.5,1$ and $2 \mathrm{~m}$ below the top of the sleepers in the center of the track, to avoid any disturbances in case off relining of the track. Drilling was carried out down to $2 \mathrm{~m}$ below the top of the sleepers. The temperature sensors were lowered into the feed pipe and the tube was filled with sand. After the installation, the feed pipe was pulled up.

\subsubsection{Installation of gauges for air pressure and air velocity in the tunnels}

To improve knowledge about air movements in track tunnels, gauges for air velocity and air pressure were installed. There were four measuring cabinets installed at both tunnels. One for each measuring station inside the track tunnel (south, north and middle) and one in the engineering house, outside the highest tunnel entrance for both tunnels. In both track tunnels, pressure gauges were installed in both the northern and southern cabinets. Air velocity was measured in three sections along the tunnels. In the Åsa tunnel, the wind gauges were installed at the handrail about $1.2 \mathrm{~m}$ above the surface of the sidewalk and approximately 1-1.5 $\mathrm{m}$ from the tunnel wall (Figure 11a). In the Glödberget tunnel, the wind gauge was installed on a steel rack about $2.5 \mathrm{~m}$ above the surface of the sidewalk and approximately $30 \mathrm{~cm}$ from the tunnel wall (Figure 11b). 


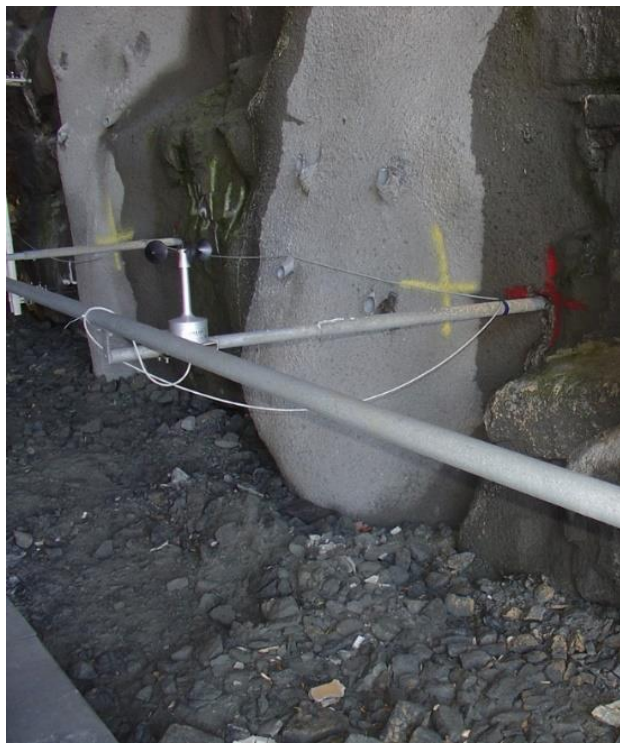

a)

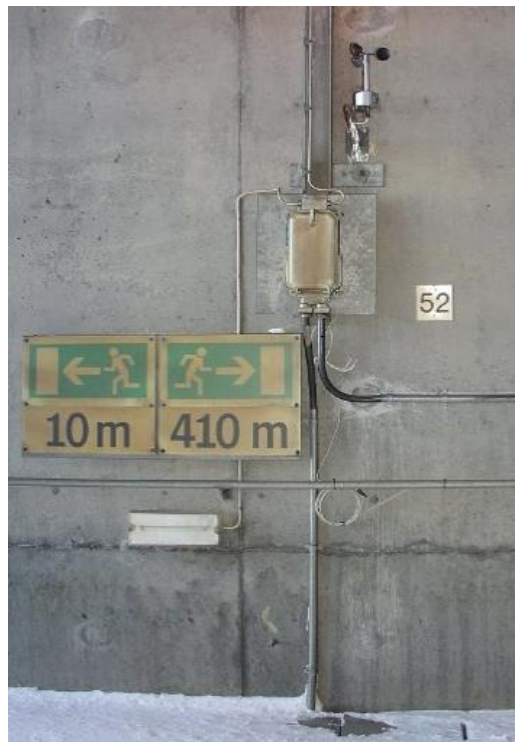

b)

Figure 11: a) Wind gauge in the Åsa tunnel, installed at the handrail; b) Wind gauge in the Glödberget tunnel, installed on a steel rack.

\section{Results and discussion of measurements}

\subsection{Measurements of tunnel air temperature}

\subsubsection{Temperature data from more than 10 years of monitoring}

Temperatures have been measured in the two tunnels for more than 10 years. In Figure 12 and Figure 13, the average daily air temperatures, outside and along the tunnels, are shown. The individual measuring series are difficult to distinguish in the charts, but they give an overview of how temperatures have varied over the years. Figure 12 shows the air temperature measurements outside and inside the Åsa tunnel from 2006-05-01 to 2017-02-01, and in Figure 13, the measurements from the Glödberget tunnel from 2007-03-01 to 2017-06-01 are shown. According to the temperature range in the figures below, it is clear that the Glödberget tunnel and the Åsa tunnel are located in two different climate zones. 


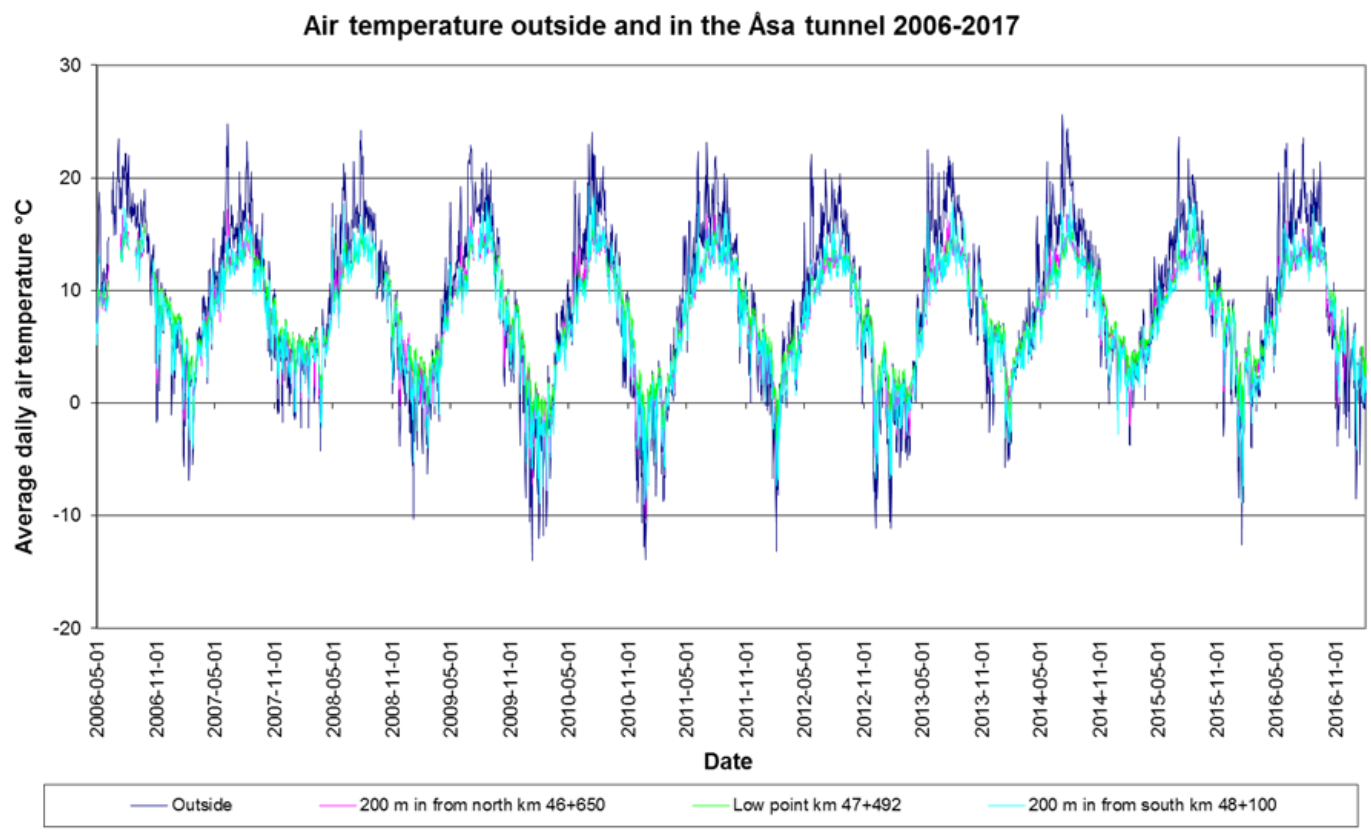

Figure 12: Average daily air temperatures outside and in the Åsa tunnel 2006-2017.

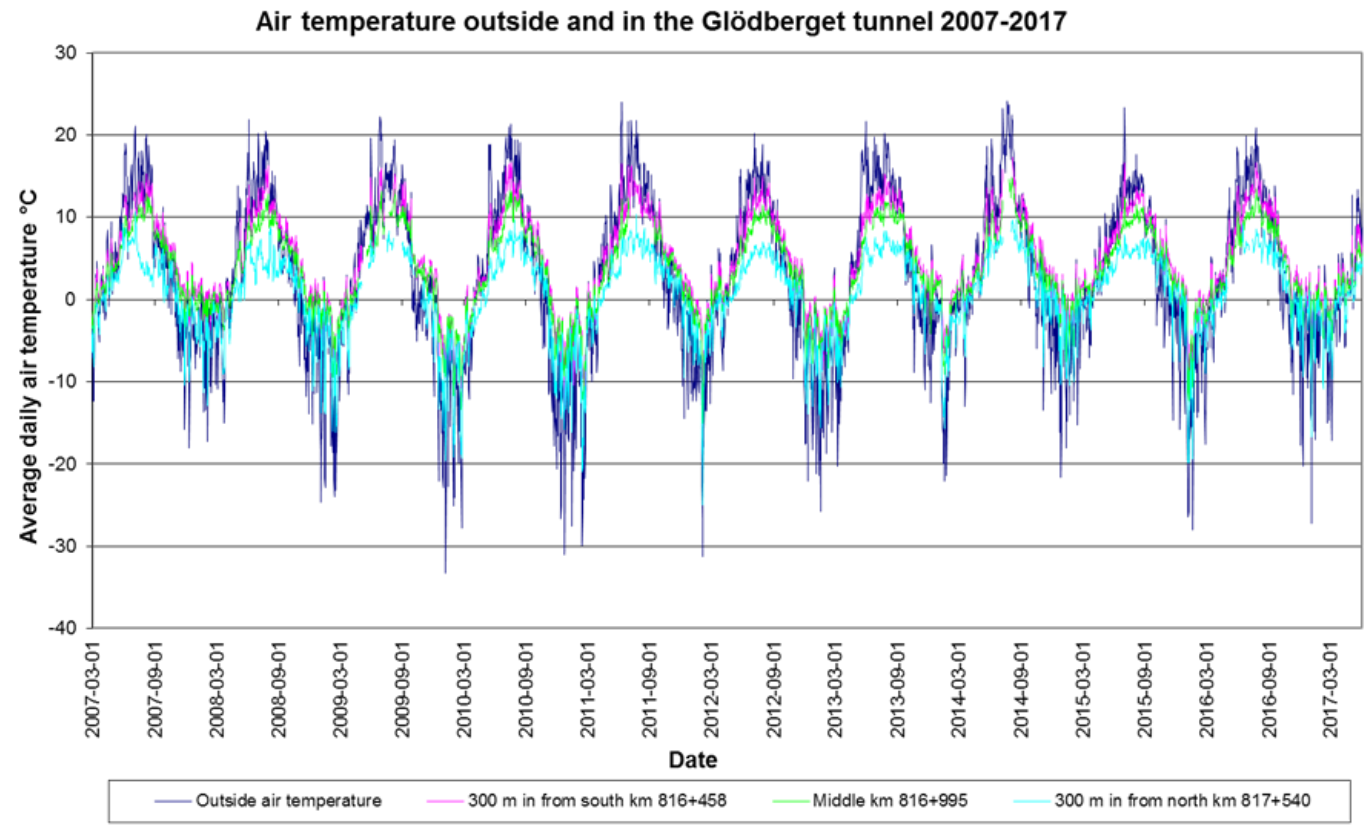

Figure 13: Average daily air temperatures outside and in the Glödberget tunnel 2006-2017. 
The measurements show that the temperatures were lowest and had the longest duration below zero degrees in the winters of 2009/2010 and 2010/2011 for both the Glödberget and the Asa tunnel. The shotcrete and the rock could be assumed to be more affected by freezing water during these winters and these periods were therefore selected for more detailed studies. Further information and results can be found in reports from the Swedish National Rail Administration and the Swedish Transport Administration [6].

Figure 14 and Figure 15 show the average daily air temperature from October 2009 to July 2011, for the Åsa and Glödberget tunnel, respectively. The Åsa tunnel has a complicated temperature situation, due to its low point. Sometimes the higher, northern entrance (the pink curve in Figure 14) is warmer than the lower, southern entrance (the cyan curve in Figure 14), and sometimes it is the other way around. Because of the low point, it seems that the air motion can change direction and move towards either of the entrances. For the Glödberget tunnel, the temperature in the higher, southern part of the tunnel (the pink curve in Figure 15) is usually higher than that at the lower, northern part (the cyan curve in Figure 15). That is because the Glödberget tunnel has a constant inclination and the heated tunnel air, moves due to the chimney effect towards the higher, southern entrance.

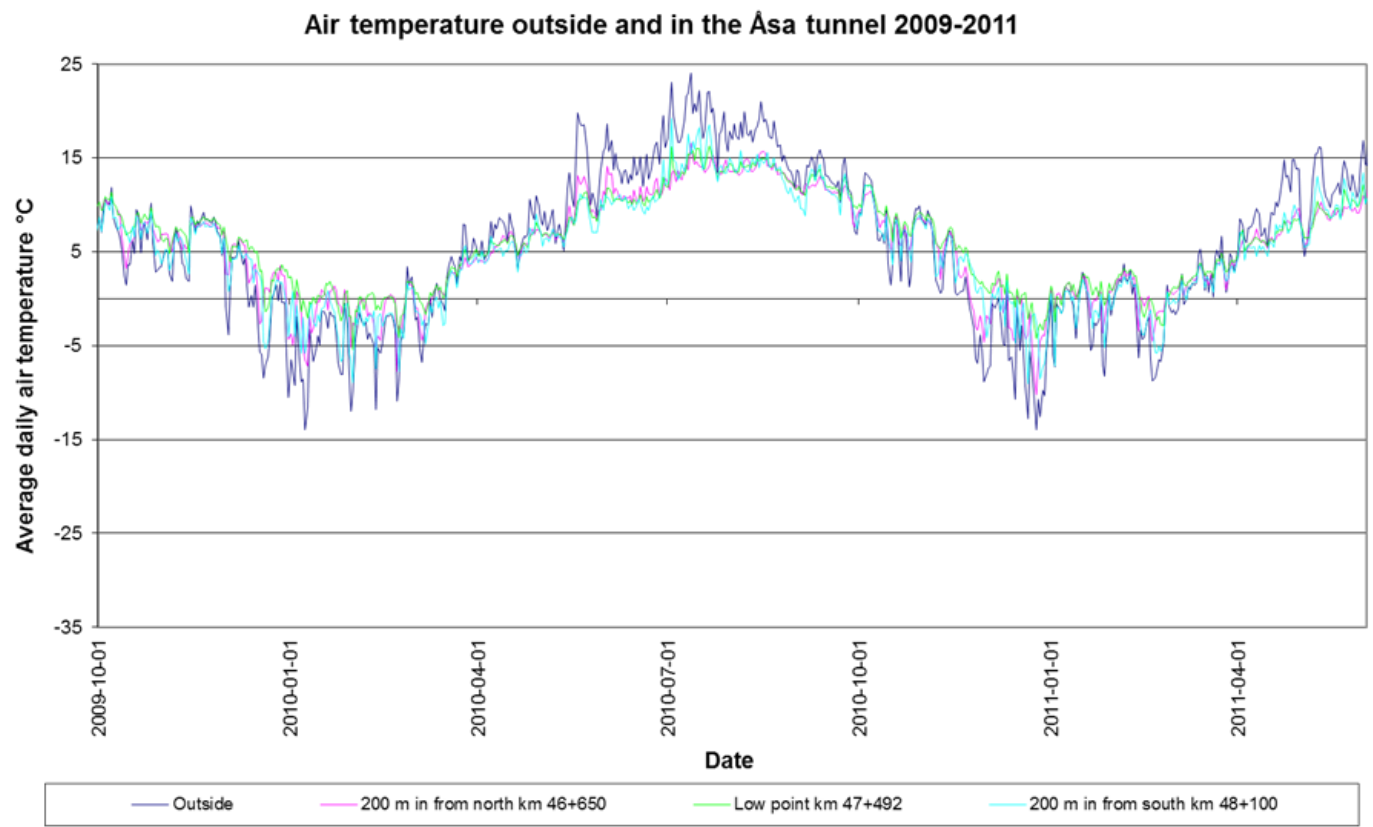

Figure 14: Average daily air temperatures outside and in the Åsa tunnel 2009-2011. 


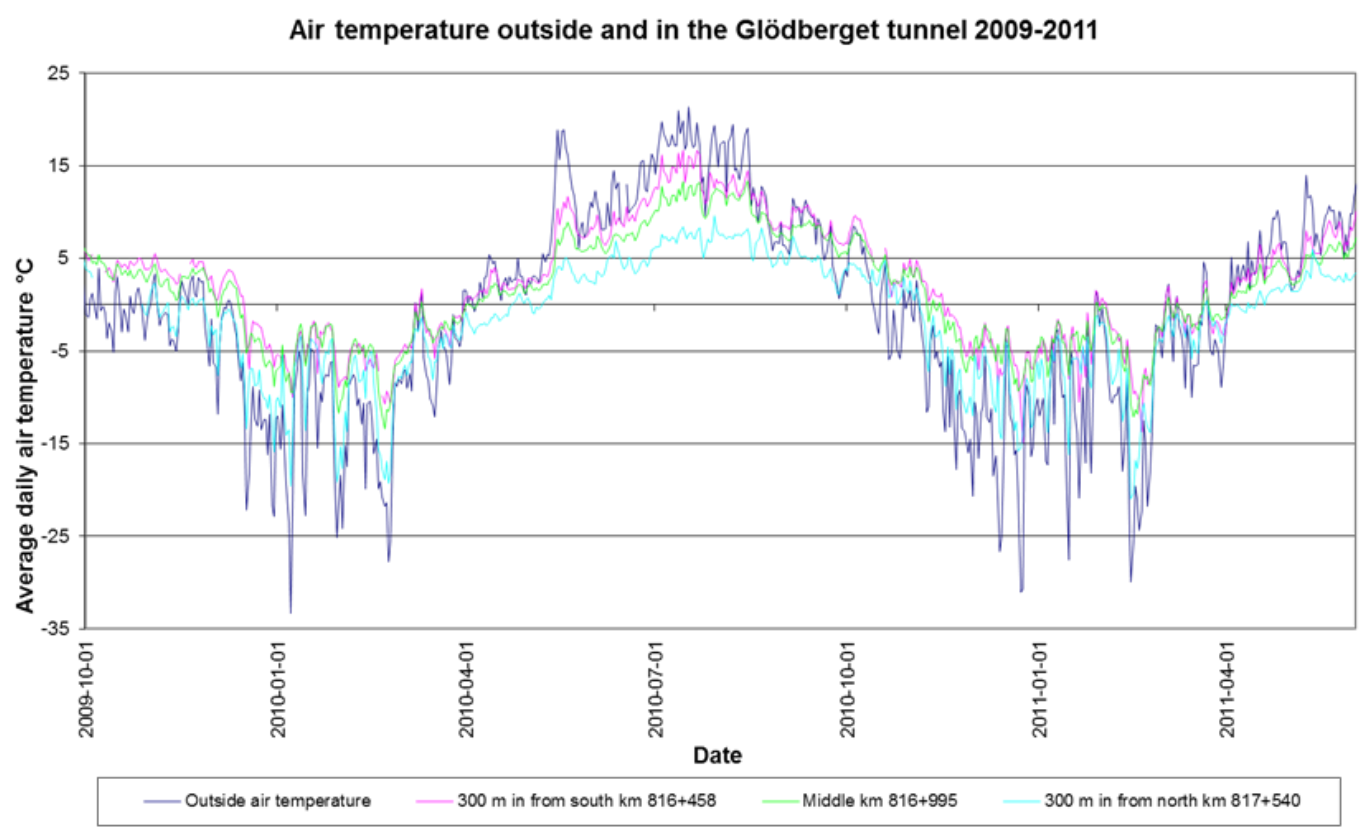

Figure 15: Average daily air temperatures outside and in the Glödberget tunnel 2009-2011.

\subsubsection{Tunnel air temperature along the Åsa tunnel}

Figure 16 shows the air temperature at the measuring stations in the Åsa tunnel for seven consecutive days in January 2010. To the left is the northern entrance with a higher elevation than the southern entrance at the right side of the chart. The temperature displayed at both ends of the chart is the temperature measured at the climate station outside the northern entrance.

The frost penetrates further into the tunnel from the lower south entrance and the measurements show that the tunnel air temperature is higher in the northern parts of the tunnel. The cold outside air is heated by the rock mass and moves towards the higher northern parts of the tunnel. At the measuring station, $200 \mathrm{~m}$ from the northern entrance, the temperature starts to decrease, probably due to cold outside air entering the tunnel along the tunnel floor. However, it is clear that a major temperature difference from north to south remain, which indicates the chimney effect. 


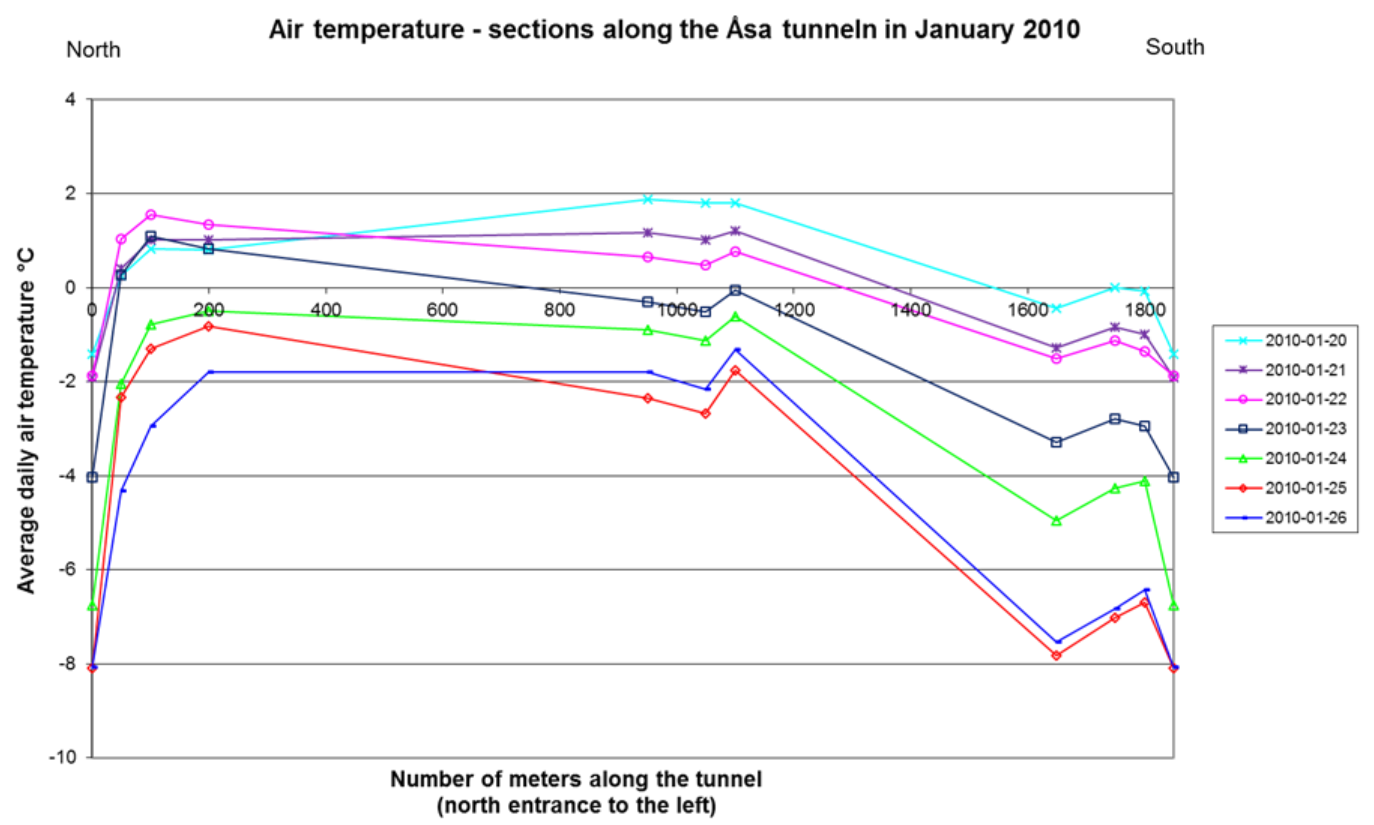

Figure 16: Air temperature in the Åsa tunnel for seven consecutive days in January 2010.

\subsubsection{Tunnel air temperature along the Glödberget tunnel}

Figure 17 shows the air temperature at the measuring stations along the Glödberget tunnel for five days in February 2017. The higher southern entrance is on the left side of the chart, and the lower northern is on the right side. The temperature displayed at both ends of the chart, is the temperature measured at the climate station outside the southern entrance.

The measurements made so far show that freezing temperatures penetrates further into the tunnels than previous assumptions in the model test [3]. Although the Glödberget tunnel is $1680 \mathrm{~m}$ long, frost penetration takes place along the whole tunnel length even at an outside temperature of a few degrees below zero. The frost penetrates further from the lower northern entrance than from the higher southern entrance. The tunnel air, heated by the rock mass, moves by convection towards the southern tunnel entrance, resulting in higher temperatures in this part. 


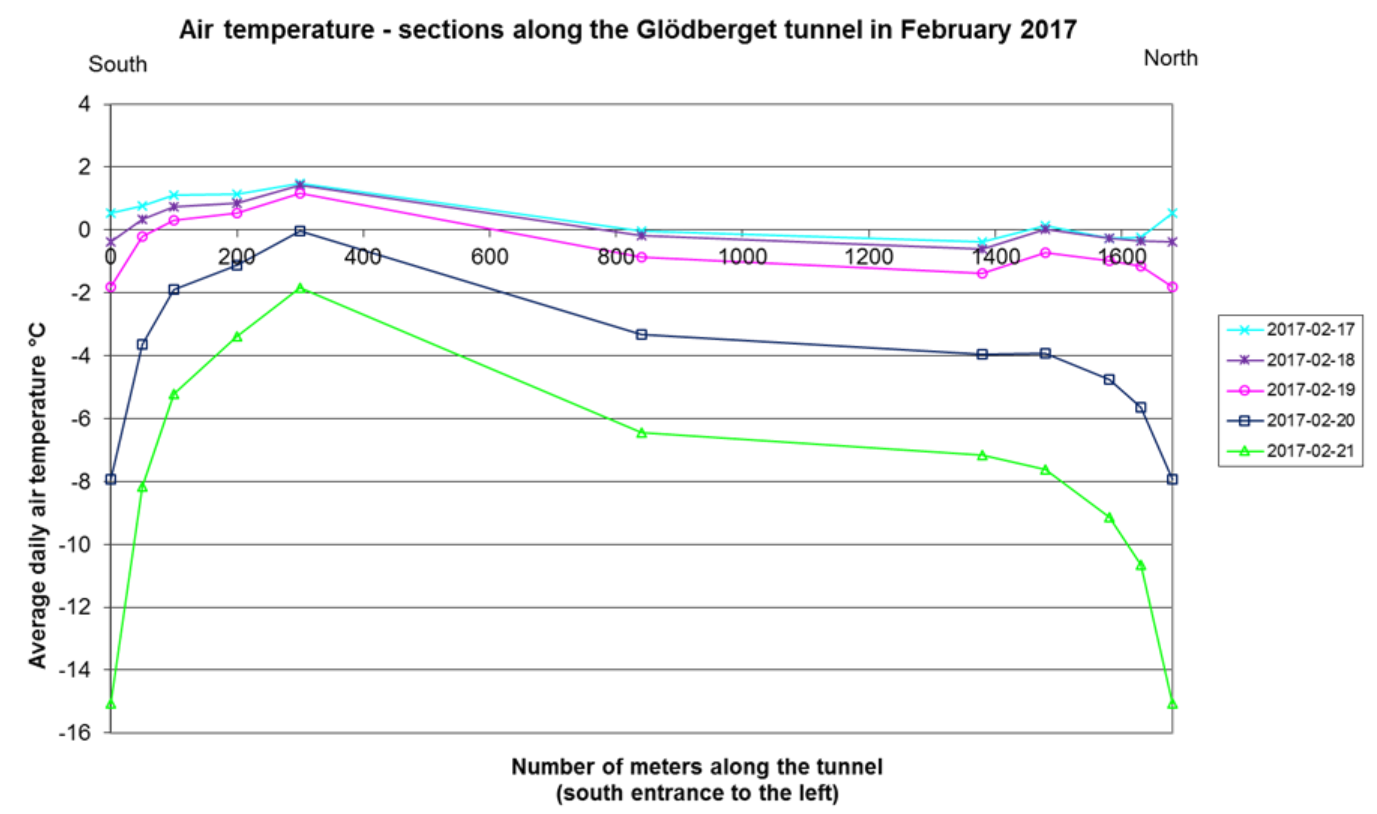

Figure 17: Air temperature in the Glödberget tunnel for five consecutive days in February 2017.

\subsection{Rock mass temperature}

The measurements of rock mass temperatures are shown in Figure 18 to Figure 25. The figures show measurements for two selected sections per tunnel during the two coldest winter periods 2009/2010 and 2010/2011. The first selected sections are located at the middle measuring stations for both tunnels. The second selected stations are located near the lower entrance of each tunnel.

\subsubsection{The Åsa tunnel}

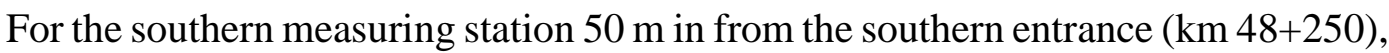
the rock mass is frozen for a long time, when the tunnel air temperature is below zero degrees for a long continuous time period (see February in Figure 18). For the same time period at the low point, about $800 \mathrm{~m}$ into the tunnel from south $(\mathrm{km}$ $47+500$ ), the rock surface and the first $10 \mathrm{~cm}$ into the rock mass stays more or less unfrozen. This is because the tunnel air temperature is several degrees warmer in this part of the tunnel, due to heat exchange from rock to air (Figure 19). 
Temperature in the rock mass at the southern part of the Asa tunnel km 48+250, 2009-2010

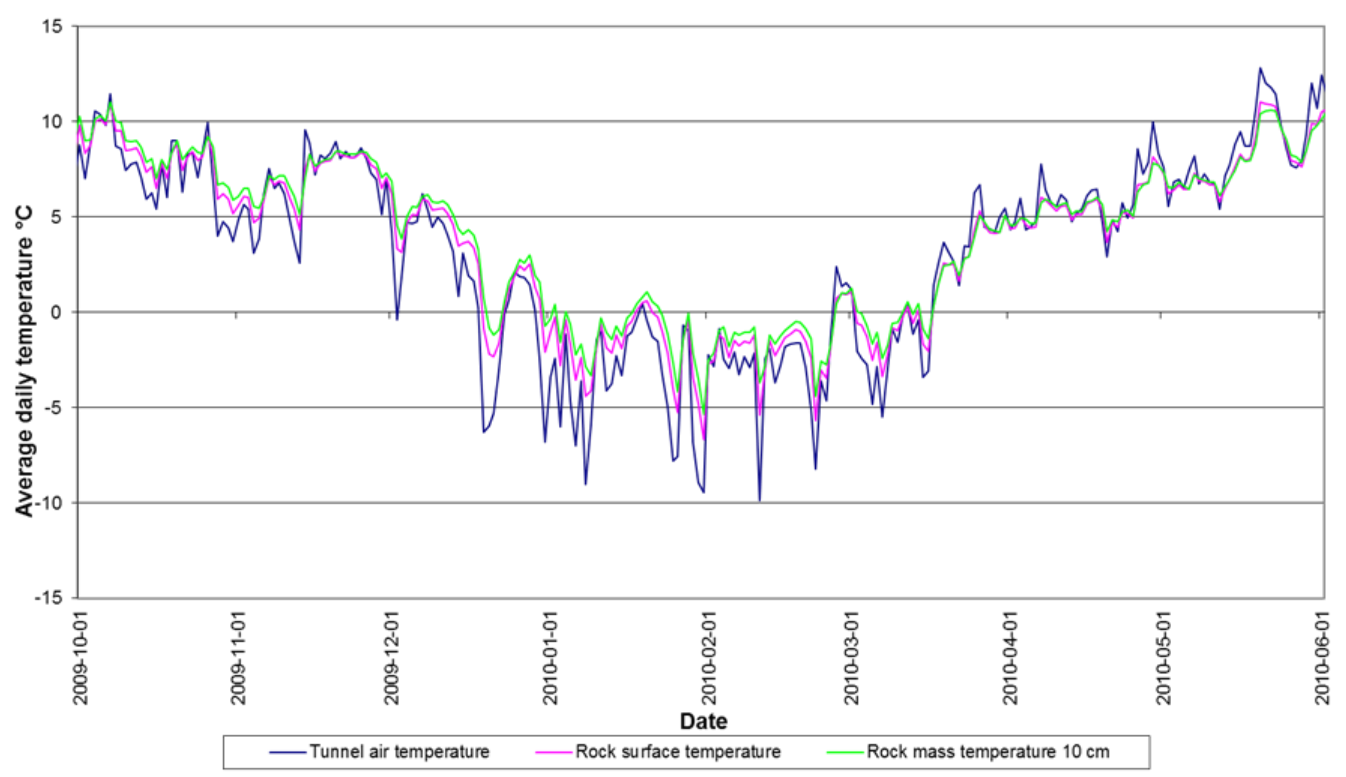

Figure 18: Rock mass temperature at the southern part of the Åsa tunnel, 2009-2010.

Temperature in the rock mass at the low point of the Asa tunnel km 47+500, 2009-2010

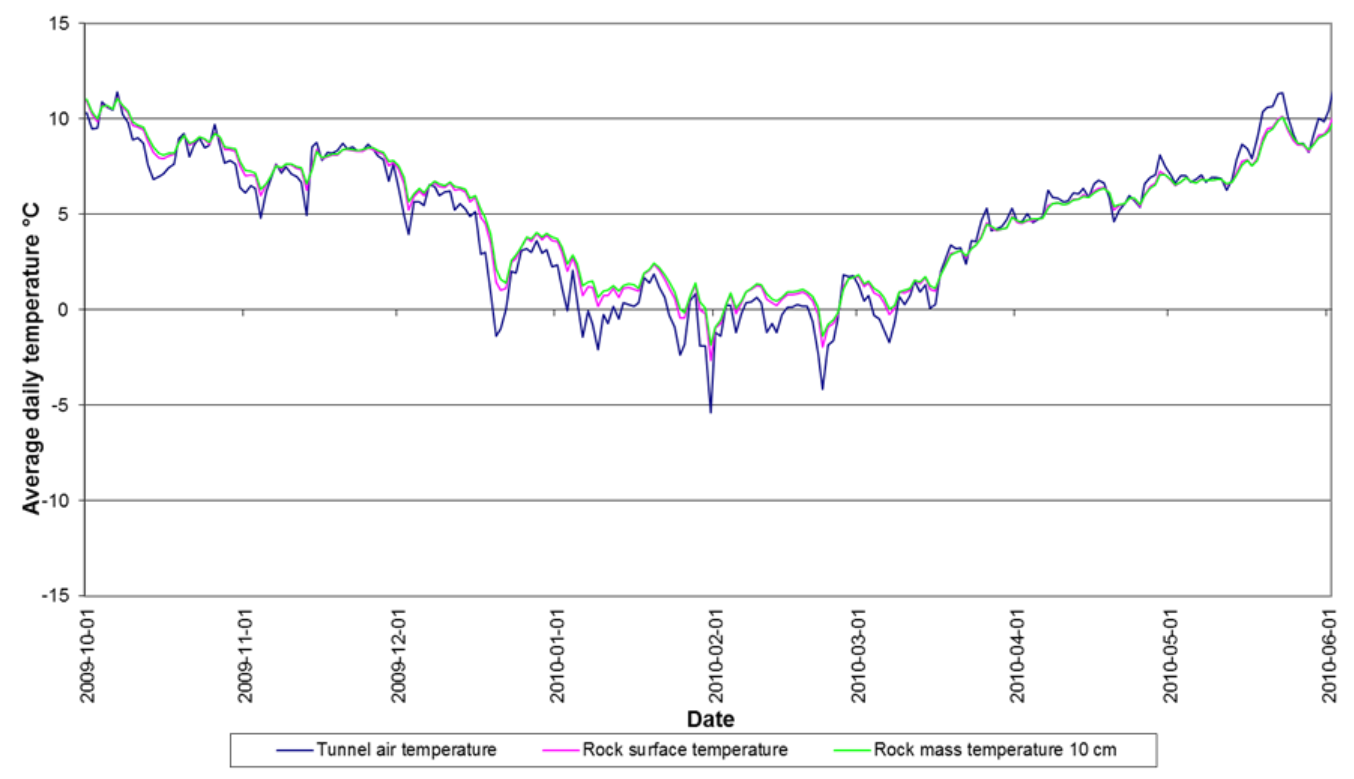

Figure 19: Rock mass temperature at the low point of the Åsa tunnel, 2009-2010. 
The same pattern is observed for the winter 2010/2011. The southern part of the tunnel is colder than at the low point and the rock mass is freezing periodically in this part (Figure 20), while the rock mass only gets frozen for shorter periods at the warmer low point (Figure 21).

Temperature in the rock mass at the southern part of the Asa tunnel km 48+250, 2010-2011

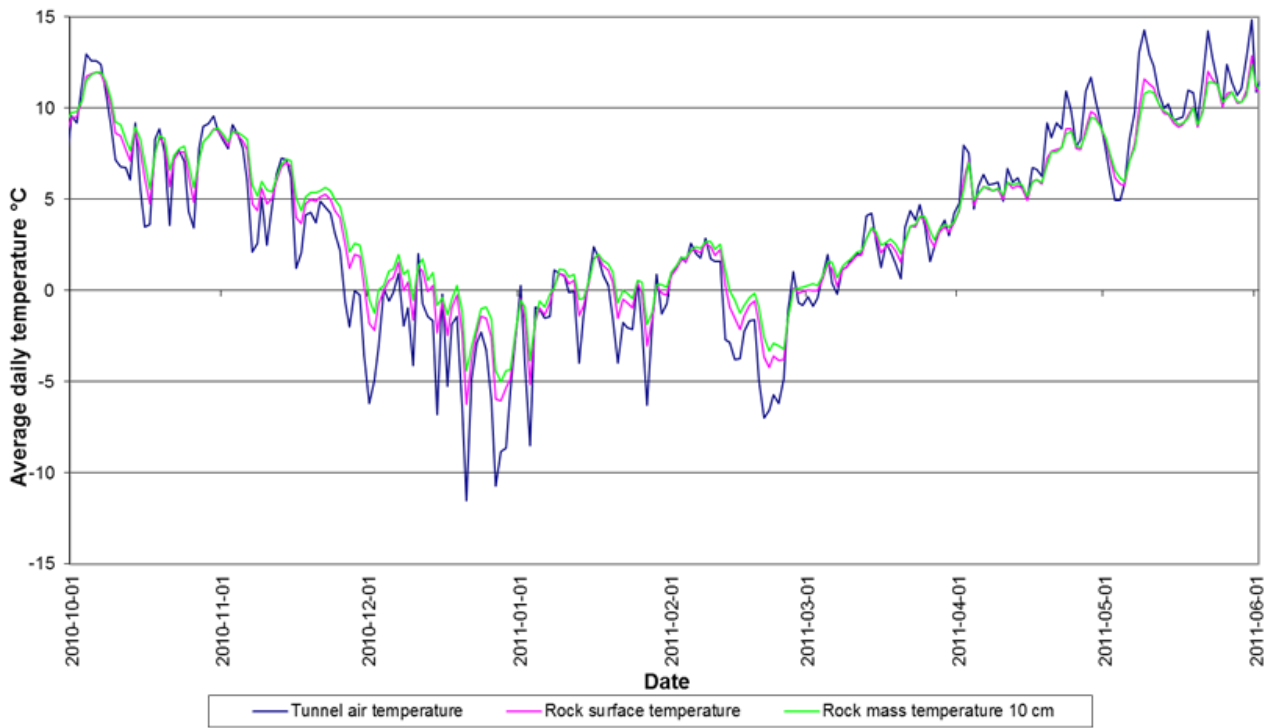

Figure 20: Rock mass temperature at the southern part of the Åsa tunnel, 2010-2011.

Temperature in the rock mass at the low point of the Asa tunnel km 47+500, 2010-2011

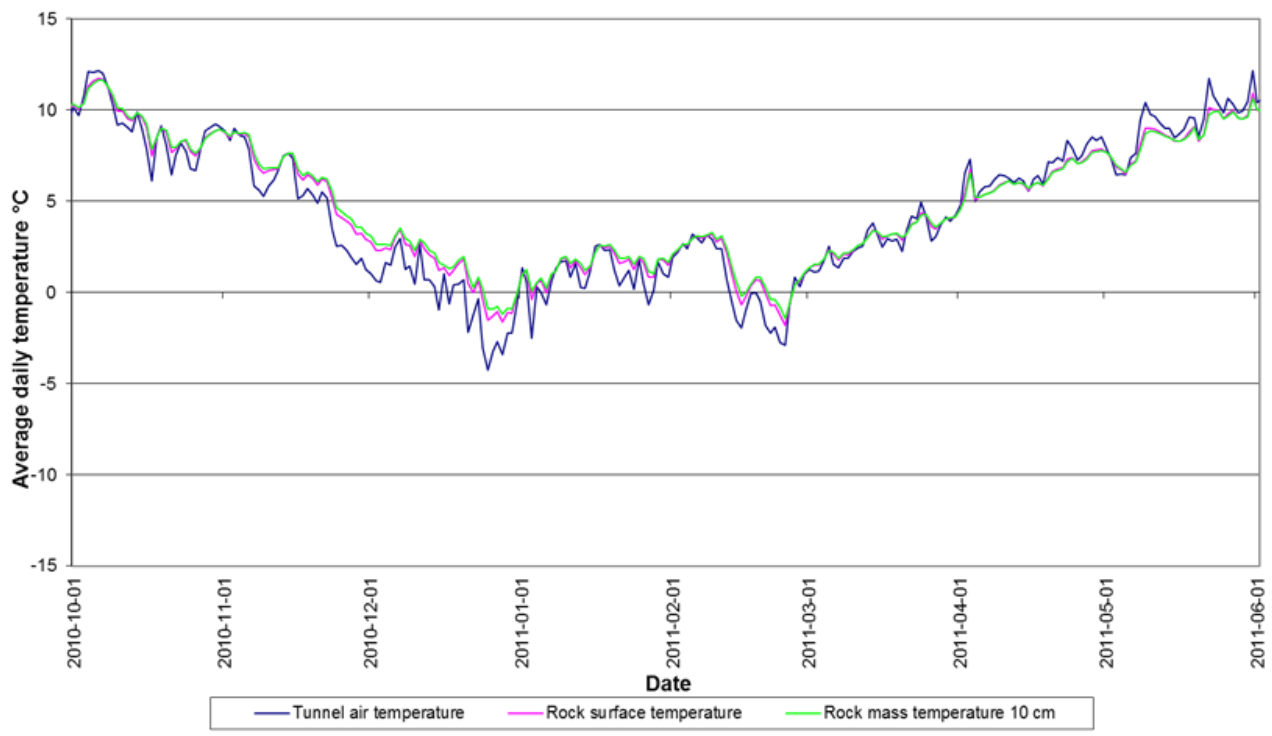

Figure 21: Rock mass temperature at the low point of the Åsa tunnel, 2010-2011. 


\subsubsection{The Glödberget tunnel}

For the middle measuring station, $840 \mathrm{~m}$ from each tunnel entrance ( $\mathrm{km} 816+995)$, the temperature measurements show that the rock mass freezes quickly, when the temperature in the tunnel air is permanently below zero degrees. This is the case even at small temperature changes of the tunnel air. In Figure 22, the temperature at a depth of $50 \mathrm{~cm}$ drops below zero degrees when the tunnel air temperature drops from $0^{\circ} \mathrm{C}$ to $-5^{\circ} \mathrm{C}$ during four days in the middle of December 2009. Correspondingly, the rock mass thaws quickly when the tunnel air temperature increases. Figure 23 shows that the same freezing process took eight days during the middle of November 2010. The depth of frost penetration in the rock mass depends on many factors. Some of these factors are the temperature of the tunnel air and the duration of the temperature drop, the rock mass properties [7], the freezing rate (decrease in temperature per unit of time, ${ }^{\circ} \mathrm{C} / \mathrm{h}$ ) $[8]$ in combination with the degree of water content [9]. The temperature drop in November 2010 (Figure 23) occurred at a lower freezing rate than in December 2009 (Figure 22) and it therefore took longer time for the freezing front to reach a depth of $50 \mathrm{~cm}$.

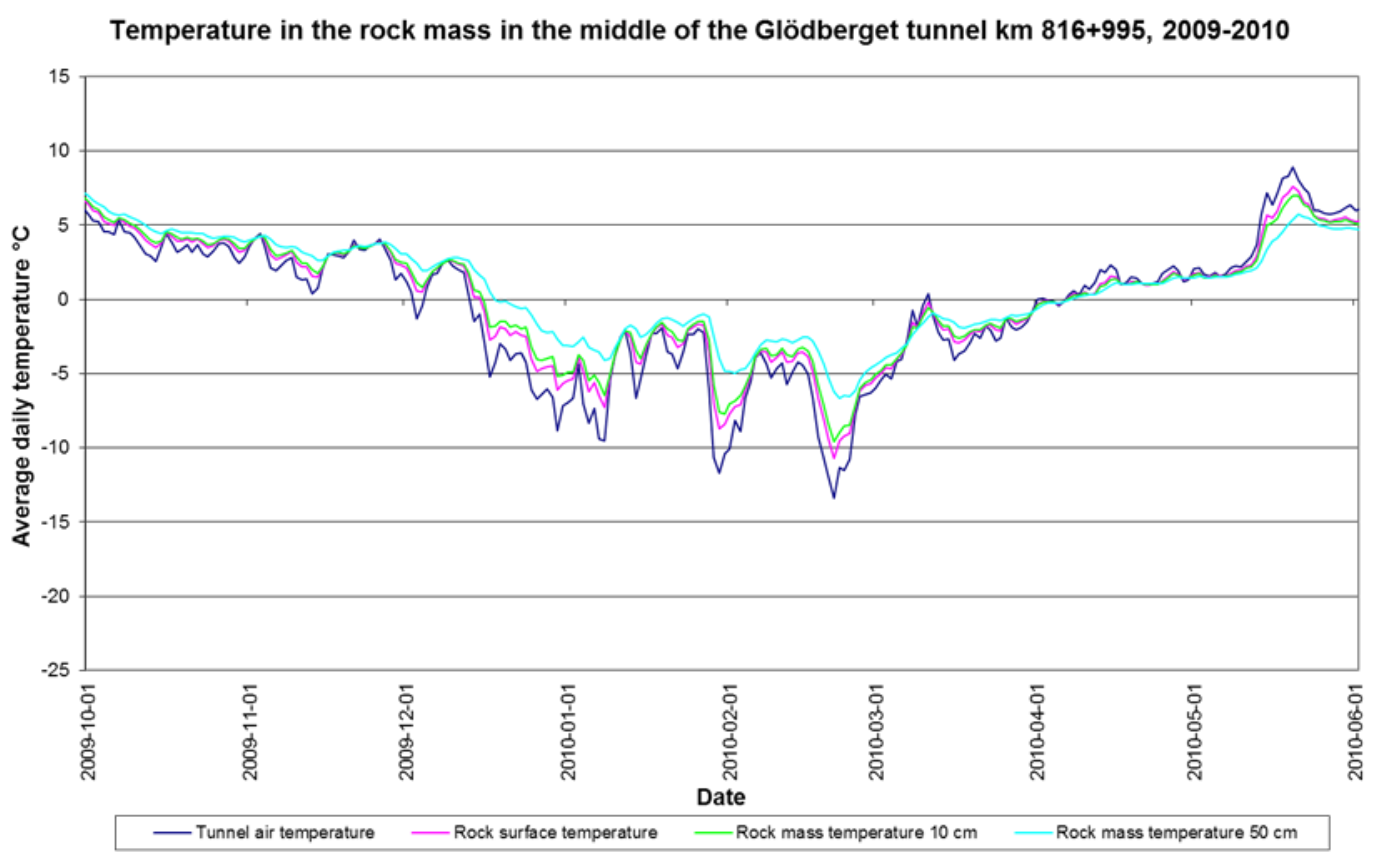

Figure 22: Rock mass temperature in the middle of the Glödberget tunnel, 2009-2010. 
Temperature in the rock mass in the middle of the Glödberget tunnel km $\mathbf{8 1 6 + 9 9 5 , 2 0 1 0 - 2 0 1 1}$

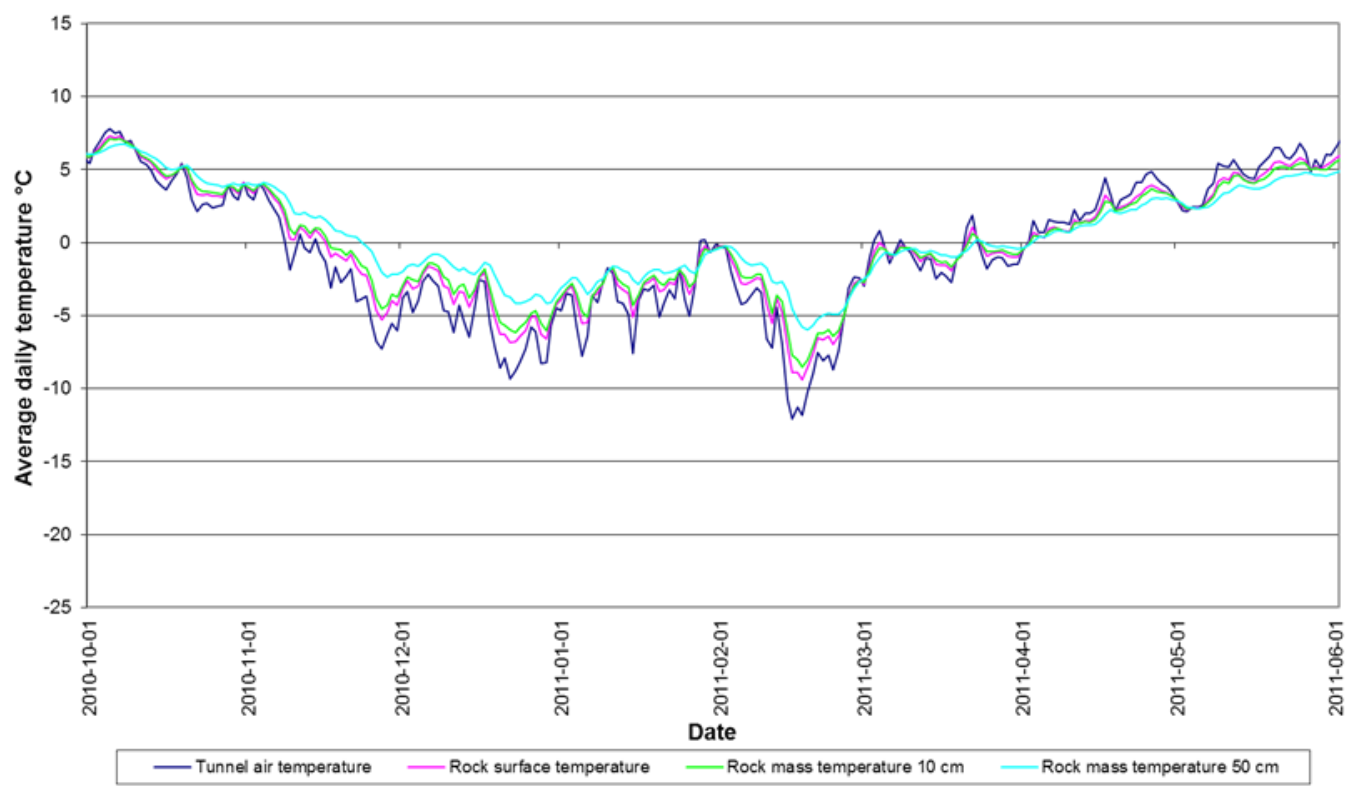

Figure 23: Rock mass temperature in the middle of the Glödberget tunnel, 2010-2011.

At the measuring station $300 \mathrm{~m}$ in from the northern tunnel entrance $(\mathrm{km} 817+540)$, the tunnel air temperature is lower than that in the middle part. Here the rock mass at $50 \mathrm{~cm}$ depth stays frozen for a longer period of time than in the middle of the tunnel, consequently, it is more likely that leakage spots remain frozen for a longer period of time in this part of the tunnel. Measurements at $50 \mathrm{~cm}$ depth show that the temperature is about $5^{\circ} \mathrm{C}$ lower at the northern part of the tunnel than in the middle during the coldest days (compare cyan curve at the end of February in Figure 24 with Figure 22 and Figure 25 with Figure 23). 
Temperature in the rock mass at the northern part of the Glödberget tunnel km $817+540,2009-2010$

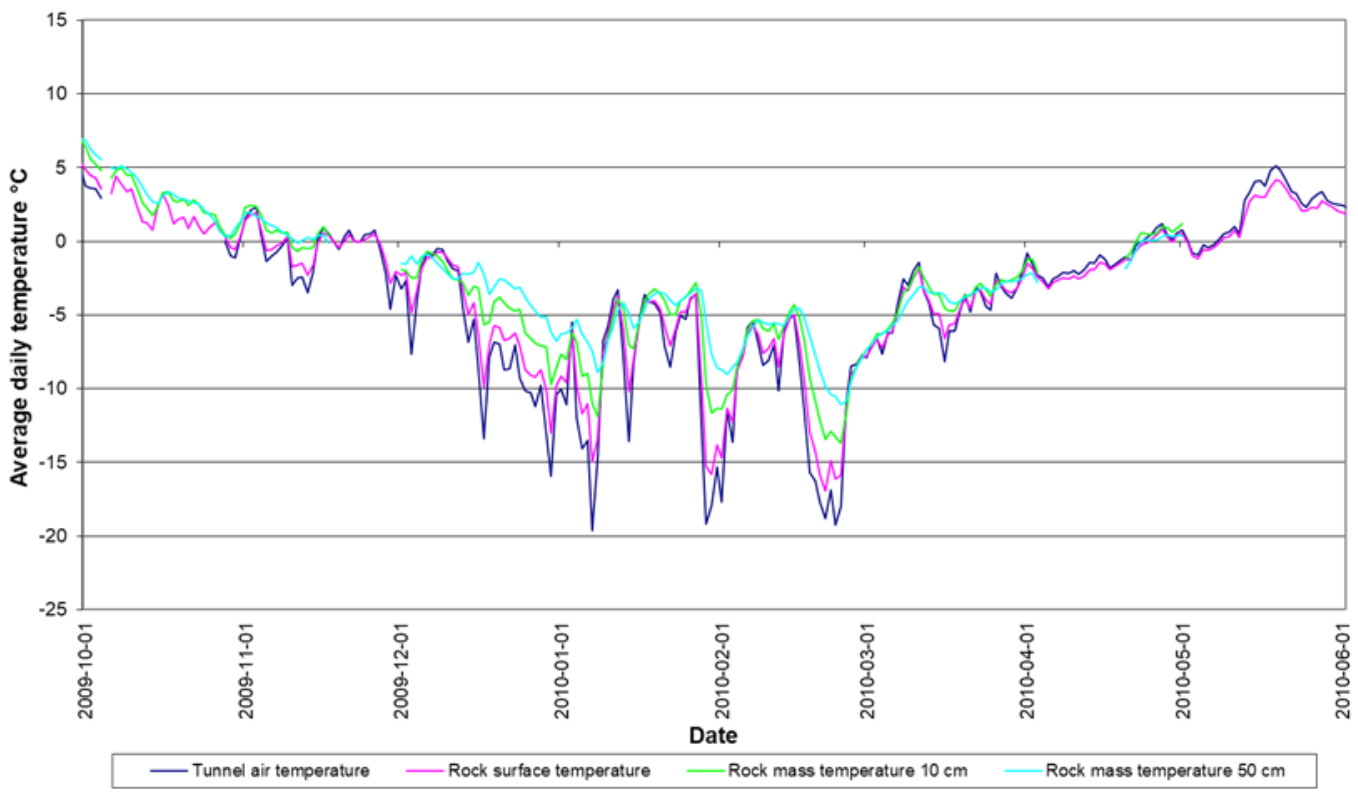

Figure 24: Rock mass temperature in the north of the Glödberget tunnel, 2009-2010.

Temperature in the rock mass at the northern part of the Glödberget tunnel $\mathbf{k m ~} \mathbf{8 1 7 + 5 4 0 , 2 0 1 0 - 2 0 1 1}$

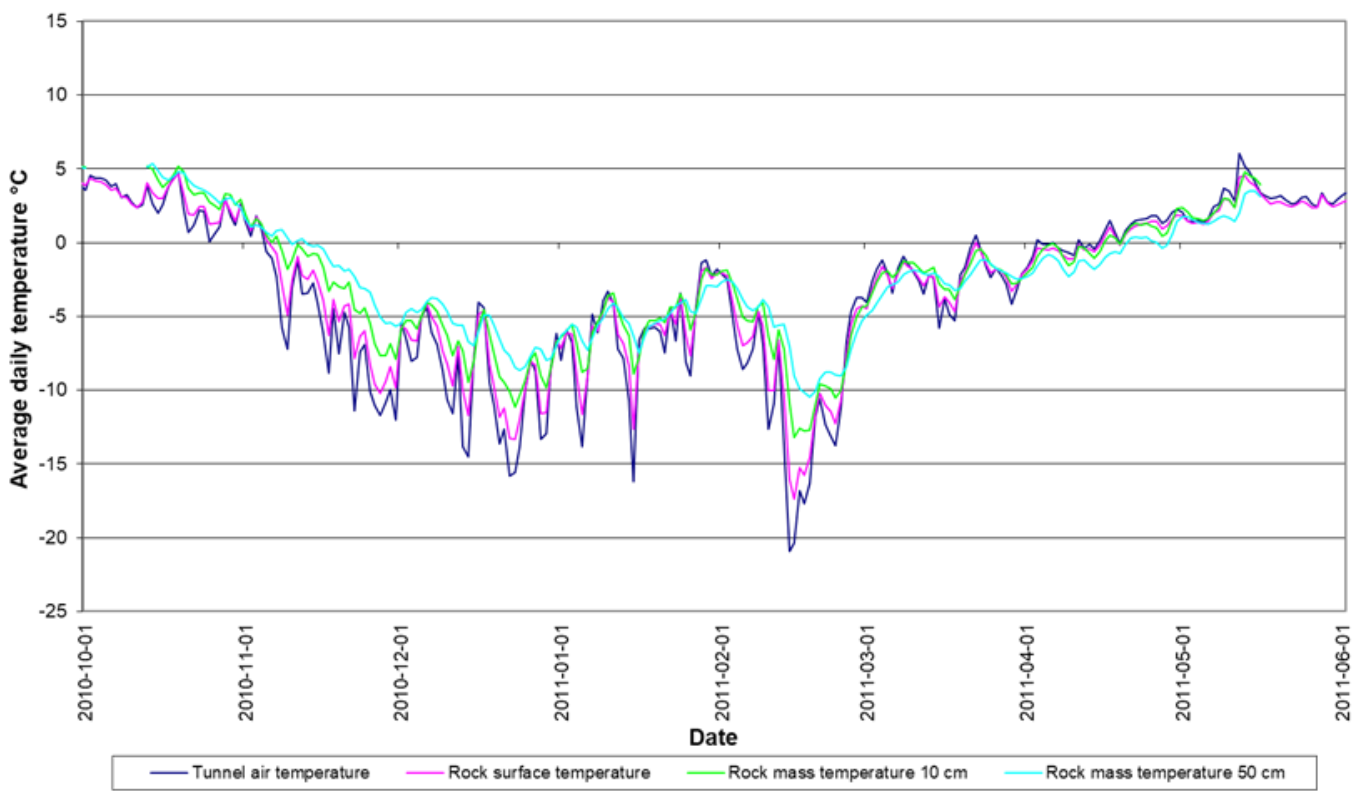

Figure 25: Rock mass temperature in the north of the Glödberget tunnel, 2010-2011. 


\subsection{Temperature behind a frost insulated drain mat in Glödberget}

In Figure 26, the temperature behind the drain is compared to the outside air temperature and the tunnel air temperature at the same section as the drain mat. The measurements show that the insulated drain is able to even out the temperature changes occurring in the tunnel air right outside the drain. The winter period 2010/2011 was longer than 2009/2010 but the temperature behind the drain drops slowly below zero degrees at the end of both winter periods. If there are sub-zero degrees behind the drain, the water from the rock mass cannot be drained properly and frost shattering may develop. Water can begin to leak on the side of the drain, with formation of ice pillars and icicles as a result (see Figure 27).

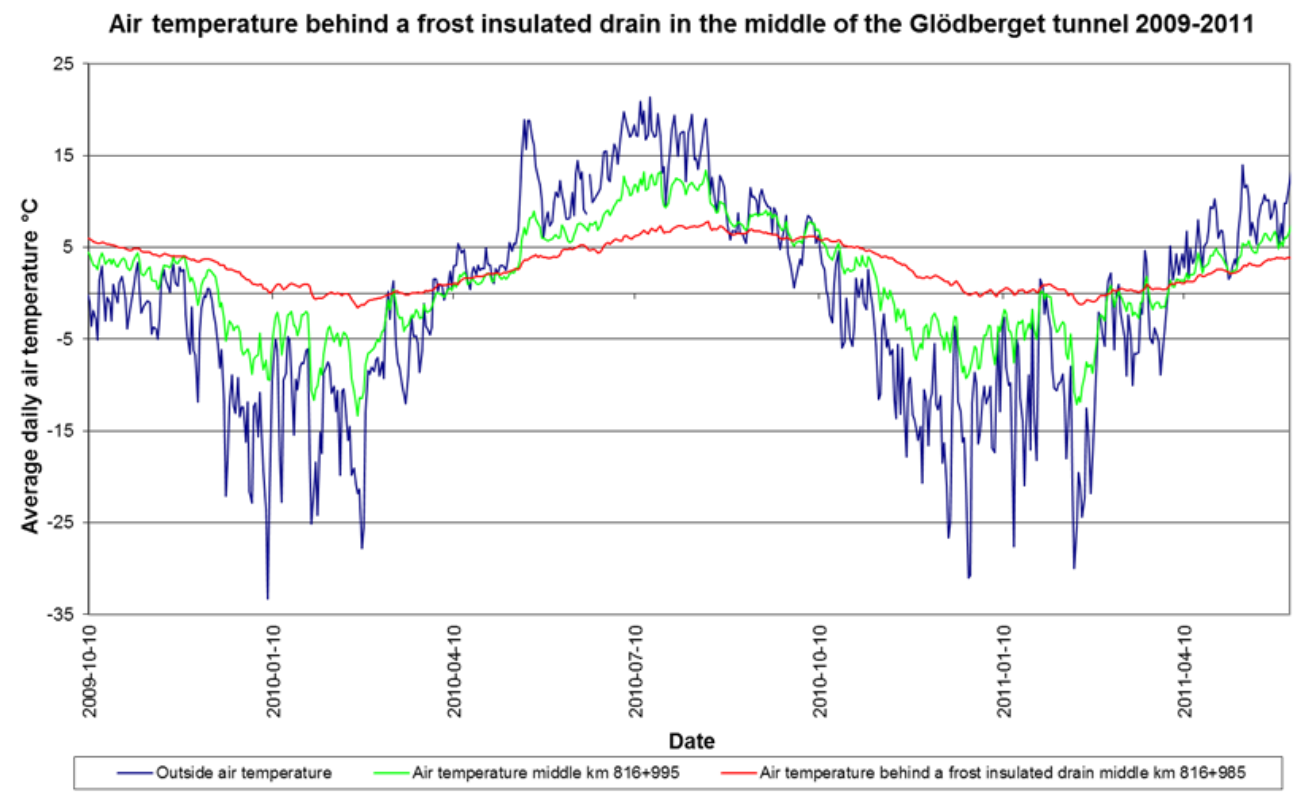

Figure 26: Temperature behind a frost insulated drain, Glödberget 20092011. 


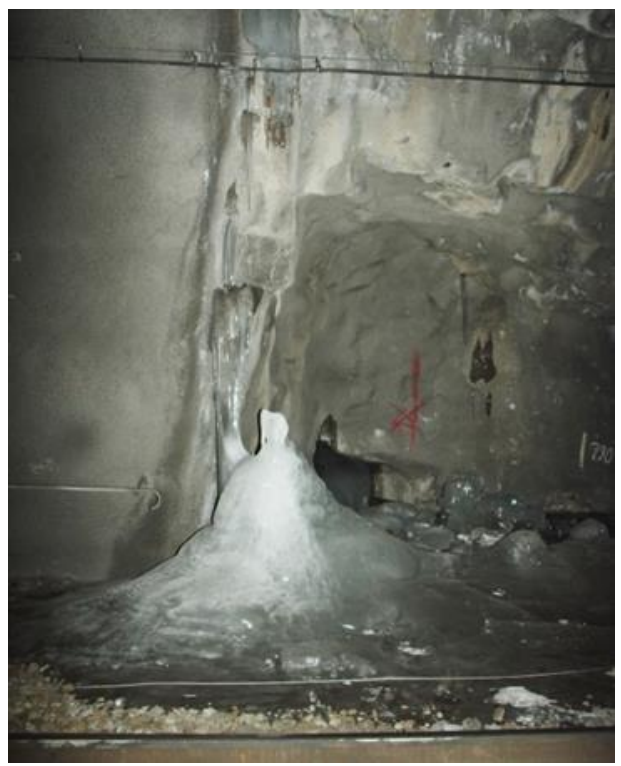

Figure 27: Ice pillar at the edge of the drain mat in the Glödberget tunnel.

\subsection{Temperature in the adjacent service tunnel in Glödberget}

The measurements show that the temperature in the service tunnel is almost constant throughout the year, around $2-3^{\circ} \mathrm{C}$ regardless of the temperature outside the tunnel. In Figure 28, the red curve is the temperature in the adjacent service tunnel and the green curve is the temperature in the track tunnel right next to the service tunnel door.

Air temperature in the adjacent service tunnel in the middle of the Glödberget tunnel 2009-2011

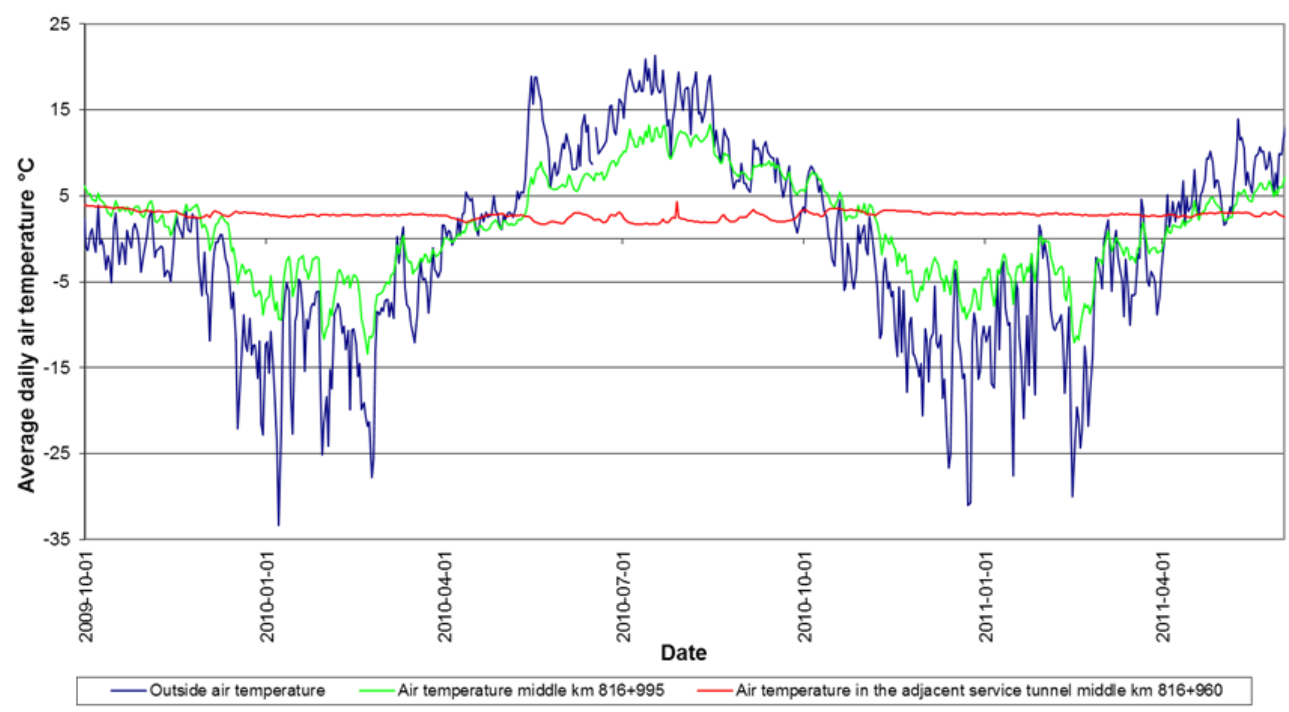

Figure 28: Temperature in the adjacent service tunnel (red curve), in comparison to outside temperature (blue) and middle section tunnel air temperature (green), Glödberget 2009-2011. 
This corresponds to the normal temperature of the rock mass and that usually coincides with the annual average temperature applicable to the region where the tunnel is located. The isotherms of the annual average temperatures, according to SMHI, the Swedish Meteorological and Hydrological institute [10], is given in Figure 29a. The figure shows that, in the region where the tunnel is located the annual average temperature is $2-3^{\circ} \mathrm{C}$, which complies well with the performed measurements in Figure 29b.

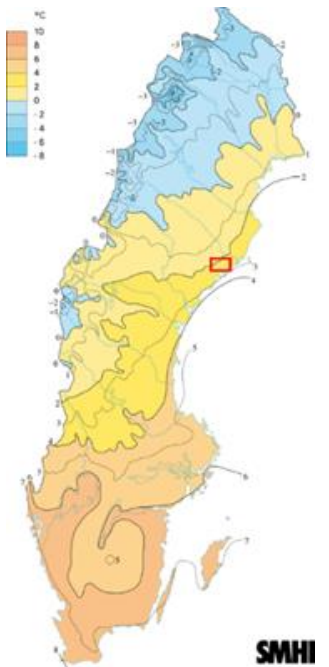

a)

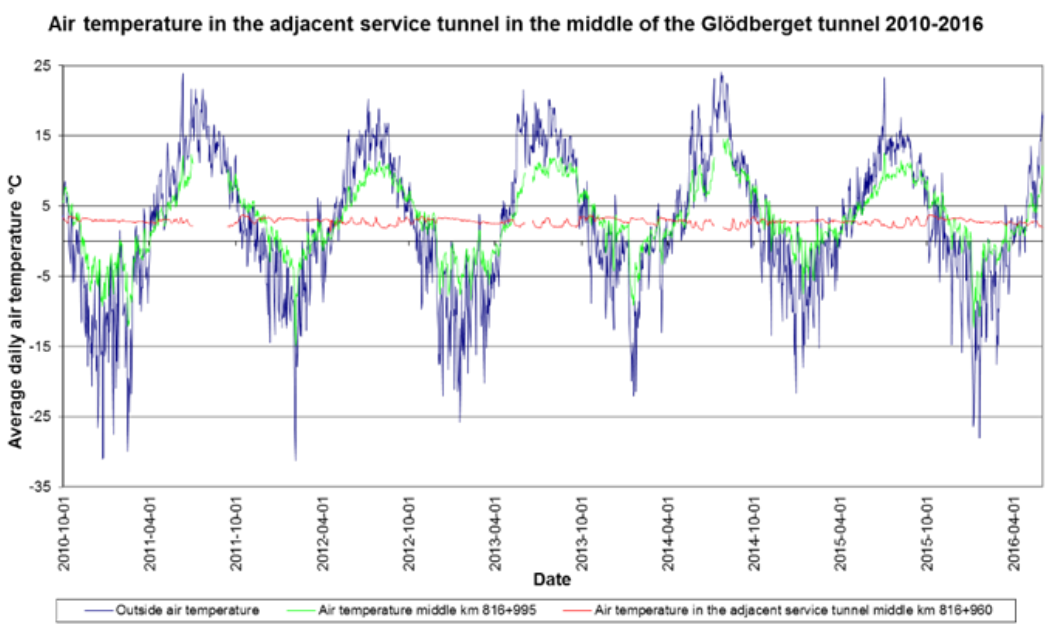

b)

Figure 29: a) The annual average temperature in Sweden - the location of the Glödberget tunnel is marked with a red rectangle [10].

b) Temperature in the adjacent service tunnel (red curve), in comparison to outside temperature (blue) and middle section tunnel air temperature (green), Glödberget 2010-2016.

\subsection{Temperature in the ballast bed in Glödberget}

Figure 30 and Figure 31 show that in the southern part of the Glödberget tunnel ( $300 \mathrm{~m}$ in from the southern tunnel entrance) the temperature at 1 and $2 \mathrm{~m}$ depth in the ballast bed is relatively unaffected by the outside and tunnel air temperature. However, as the temperatures drop throughout the winter period, the temperature at $1 \mathrm{~m}$ depth drops below zero degrees at the end of the winter, but the frozen zone never reaches $2 \mathrm{~m}$ depth. For the sensor located $0.5 \mathrm{~m}$ below the ballast surface, it takes relatively long time (about 20 days) for the temperature to drop below zero degrees. The results for the thawing phase at $0.5 \mathrm{~m}$ depth, are missing in this part of the tunnel, since the sensor at this particular depth sometimes had a bad connection. 


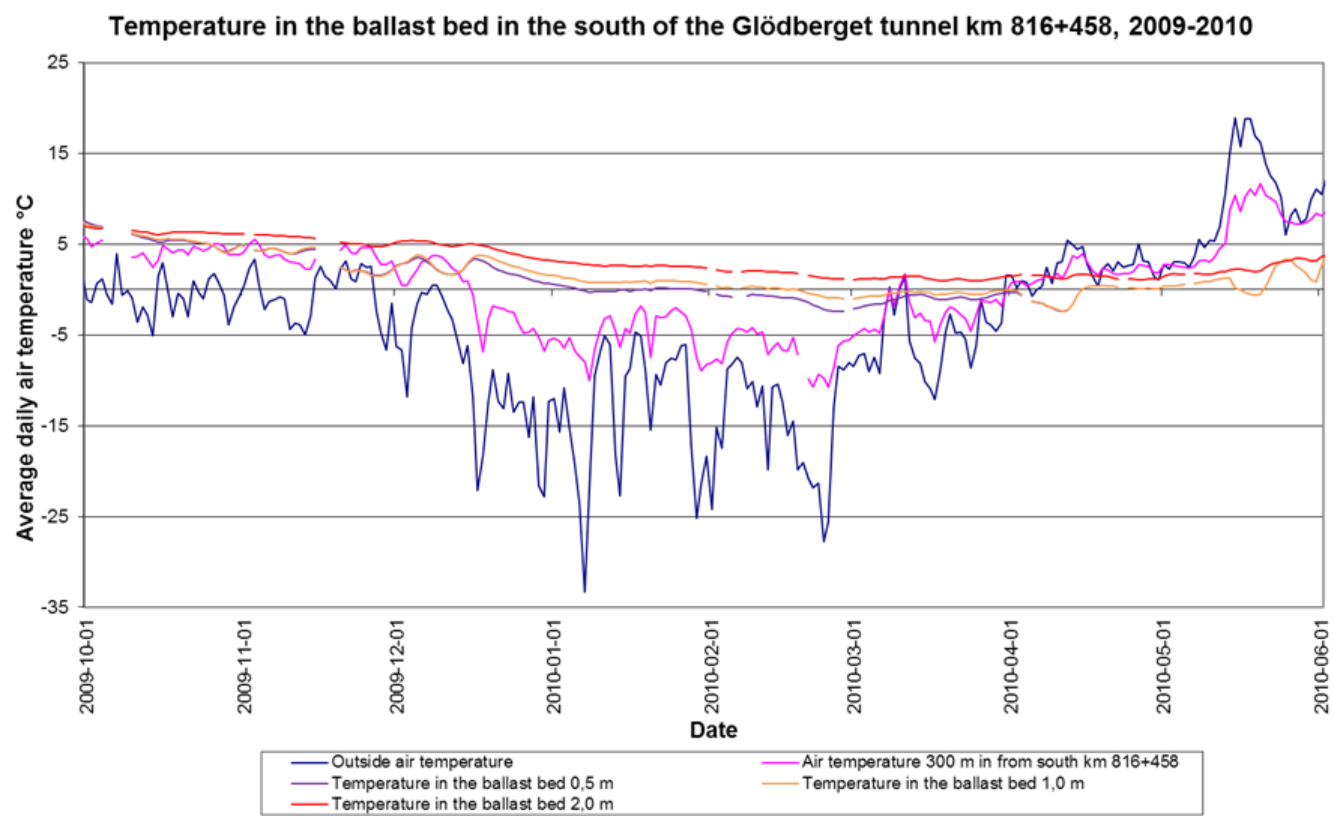

Figure 30: Temperature in the ballast bed in the south of the Glödberget tunnel, 2009-2010.

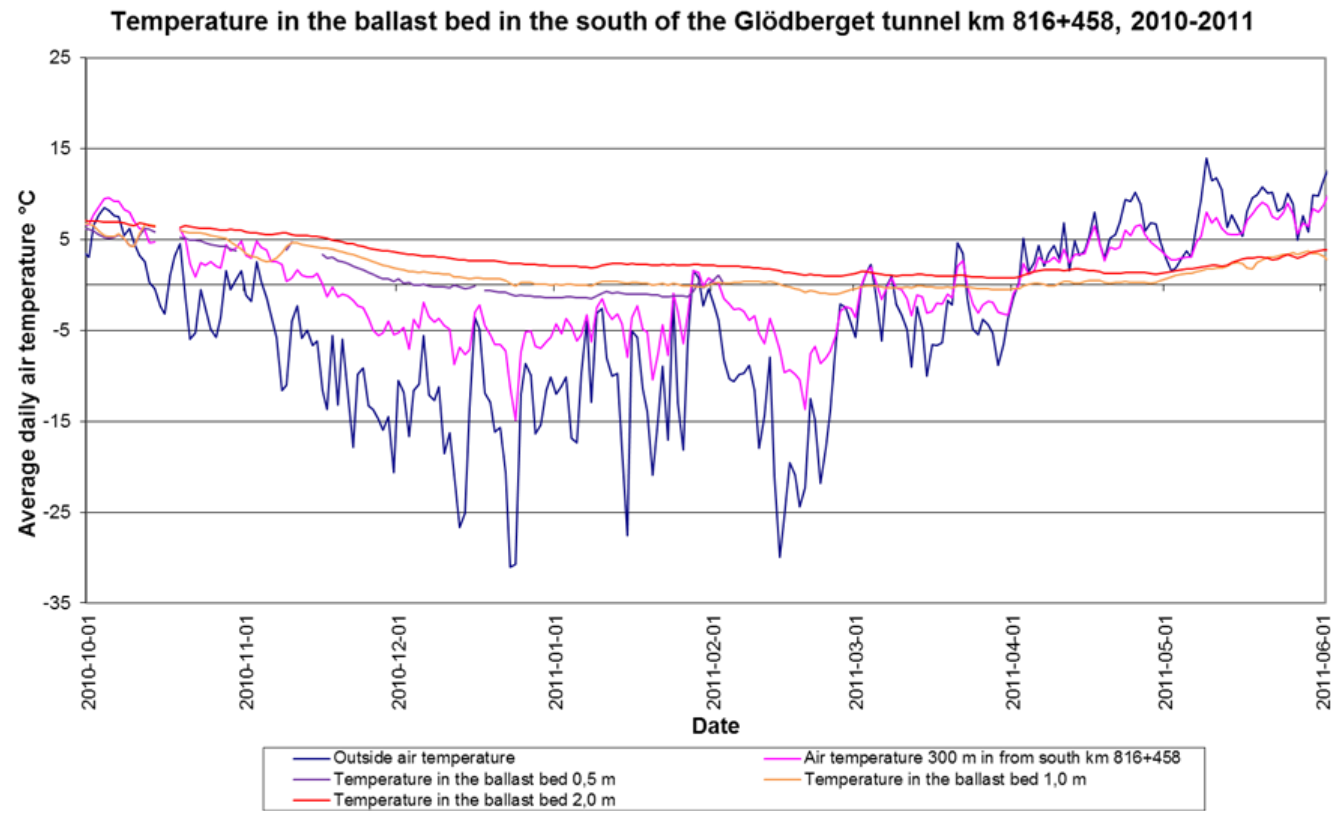

Figure 31: Temperature in the ballast bed in the south of the Glödberget tunnel, 2010-2011. 
In the middle of the Glödberget tunnel ( $\mathrm{km} \mathrm{816+995),} \mathrm{Figure} 32$ and Figure 33, the temperature at $0.5 \mathrm{~m}$ depth is relatively unaffected by the outside and tunnel air temperature and all the measured temperatures gradually drop during the winter. The temperature at $1 \mathrm{~m}$ depth drops below zero degrees at the end of the winter, and the frozen zone never reaches $2 \mathrm{~m}$ depth. For the sensor located $0.5 \mathrm{~m}$ below the ballast surface, it takes a long time (about 30-40 days) for the temperature to drop below zero degrees. The results for the thawing phase at $0.5 \mathrm{~m}$ depth show that it takes about 20-25 days for the temperature to increase above zero degrees.

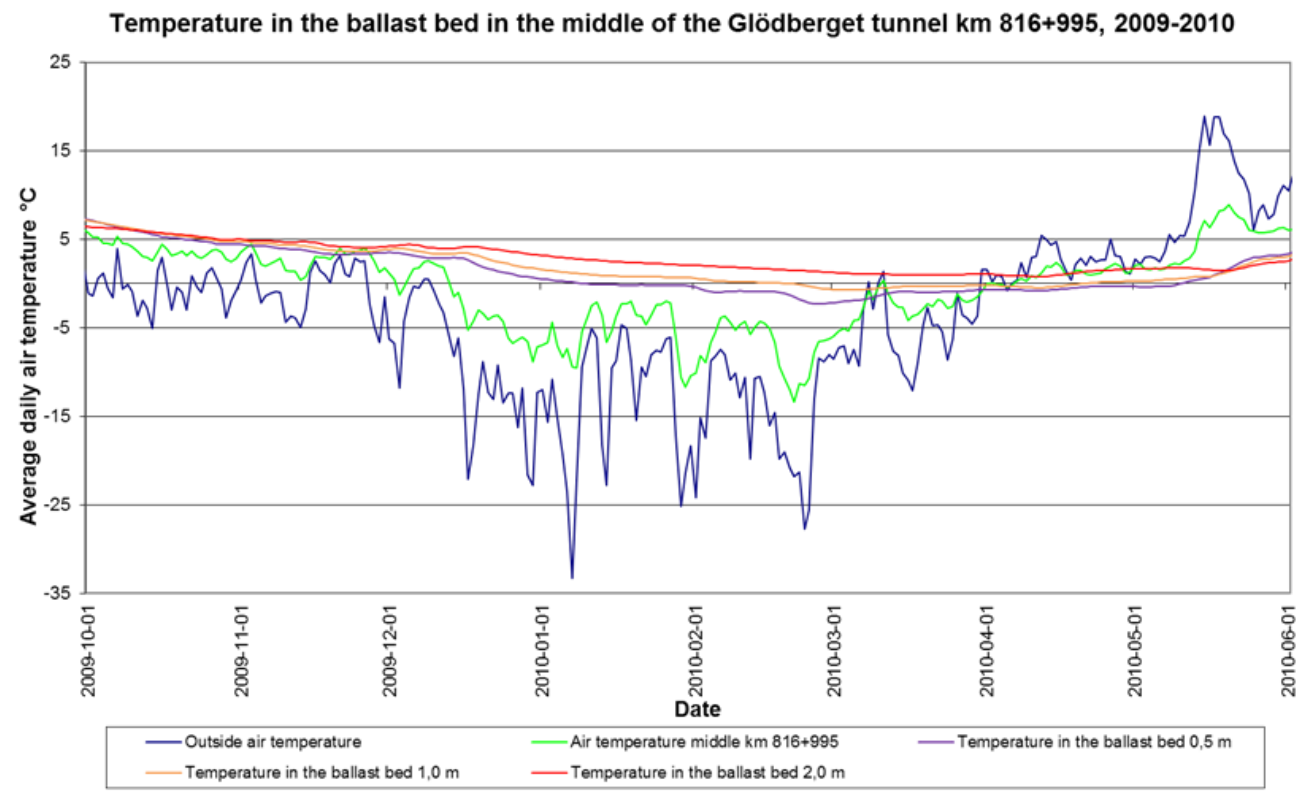

Figure 32: Temperature in the ballast bed in the middle of the Glödberget tunnel, 2009-2010. 


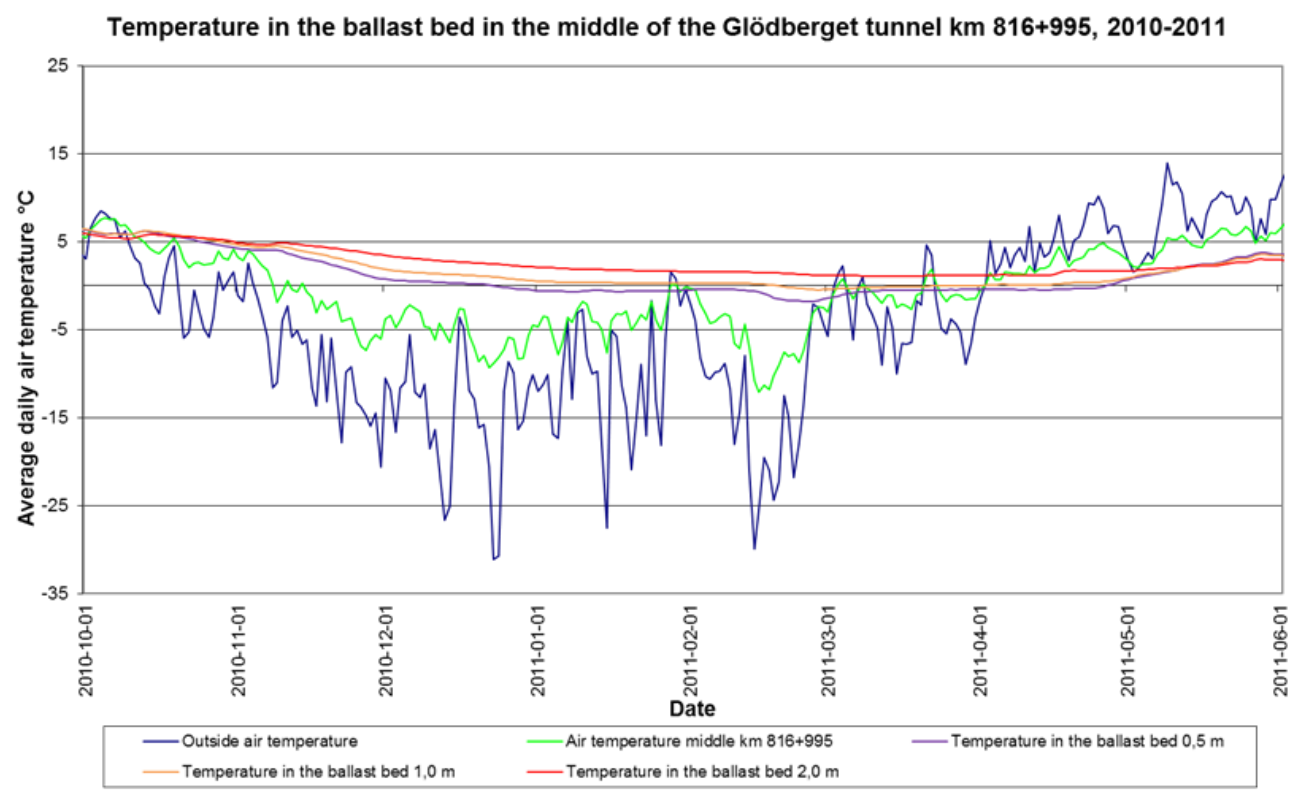

Figure 33: Temperature in the ballast bed in the middle of the Glödberget tunnel, 2010-2011.

\subsection{Wind and air velocity outside and inside the tunnels}

Figure 34 and Figure 35 show the wind and air velocity outside and inside the respective tunnels. The results from the different measuring series show that the curves are following each other to some extent, but the wind velocity outside the tunnel does not significantly affect the air velocity inside the tunnel. The air velocity is usually lower in the middle of the tunnels (green curve) than at the entrances (pink and cyan curve), where the pattern of air movement is more complex. The highest air velocity usually occurs at the measuring stations located at the highest elevation (pink curve), due to the chimney effect.

When comparing the results from the middle measuring stations (green curves in Figure 34 and Figure 35) of the two tunnels, the air velocity is higher in the Åsa tunnel than in the Glödberget tunnel. The higher air flow is caused by the complex air situation arising due to the low point in the Åsa tunnel. The Glödberget tunnel has a constant inclination, resulting in a more constant flow in the middle parts of the tunnel. 
Wind and air velocity outside and inside the Asa tunnel 2007-2012

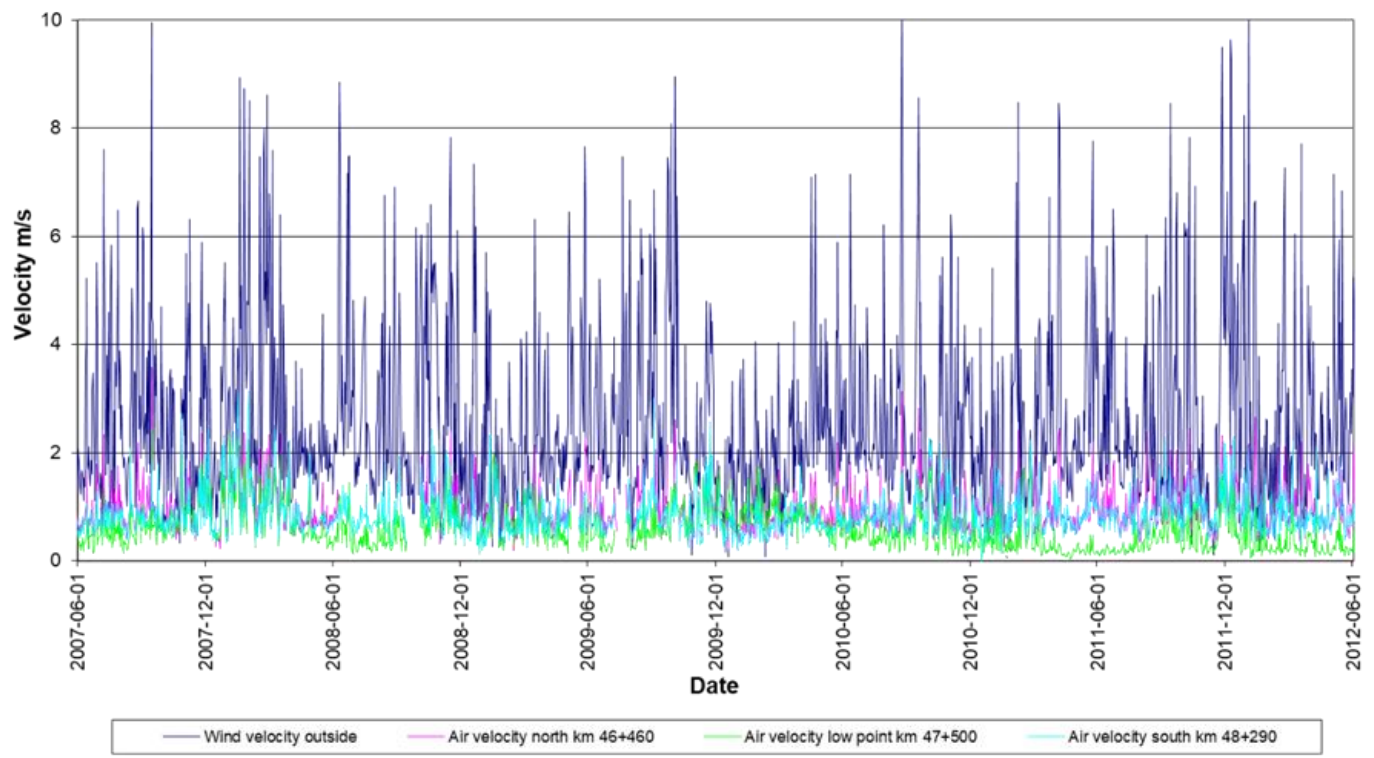

Figure 34: Wind and air velocity outside and inside the Åsa tunnel during 2007-2012.

Wind and air velocity outside and inside the Glödberget tunnel 2007-2012

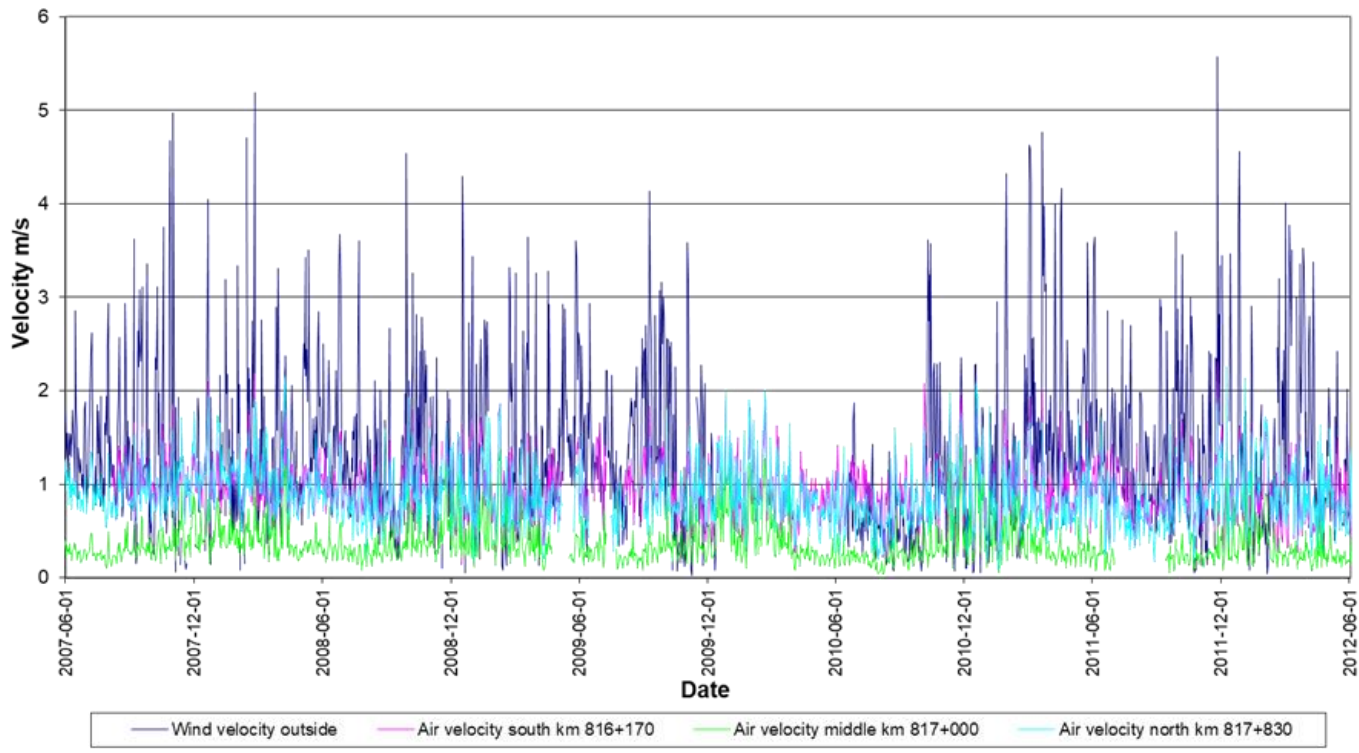

Figure 35: Wind and air velocity outside and inside the Glödberget tunnel during 2007-2012. 
During the summer periods, the air velocity at the middle measuring station (green curve) is lower than at both the higher (pink curve) and the lower measuring station (cyan curve). During the winter periods, the measurements show an increased air velocity at the middle station, which indicates increased air movements throughout the whole tunnel length during this time. This is because the temperature difference between the outside and tunnel air (heated by the rock mass) is greater during the winter, which causes the heated tunnel air to move by convection through the tunnel and start the chimney effect. This phenomenon is most evident at the Glödberget tunnel because of the large difference in elevation between the entrances (Figure 35).

For the Glödberget tunnel, it is even more apparent when plotting the air velocity versus the outside air temperature in the same chart. The air velocity of the southern (Figure 36) and northern (Figure 37) stations oscillates around $1 \mathrm{~m} / \mathrm{s}$ throughout the year. For comparison, the air velocity at the middle measuring station is around 0.2 $\mathrm{m} / \mathrm{s}$ during the summer and increases to about $0.5 \mathrm{~m} / \mathrm{s}$ when the outside air temperature drops during the winter (Figure 38). There is clearly more air movement along the whole tunnel during the winter periods.

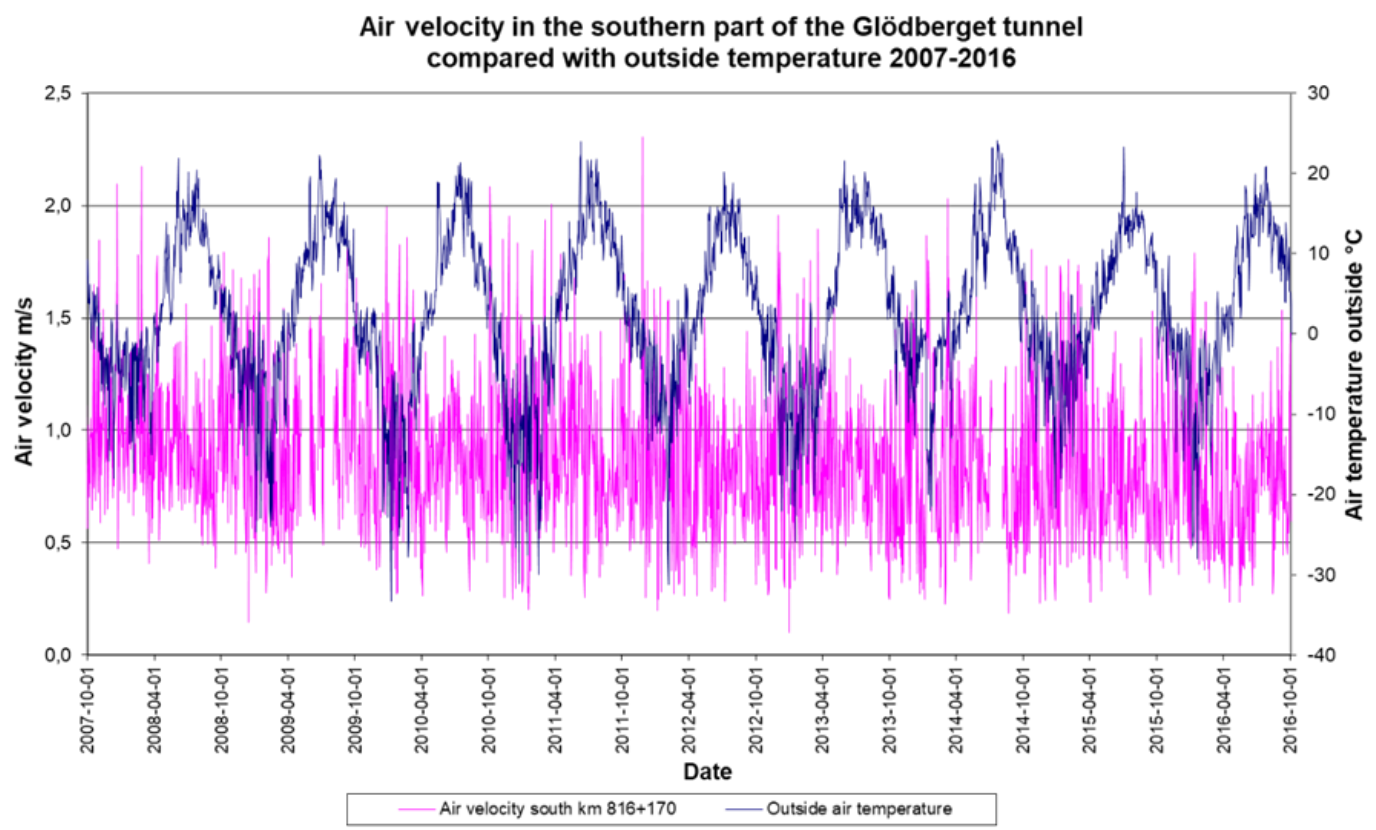

Figure 36: Air velocity in the southern part of the Glödberget tunnel, compared with outside temperature, 2007-2016. 


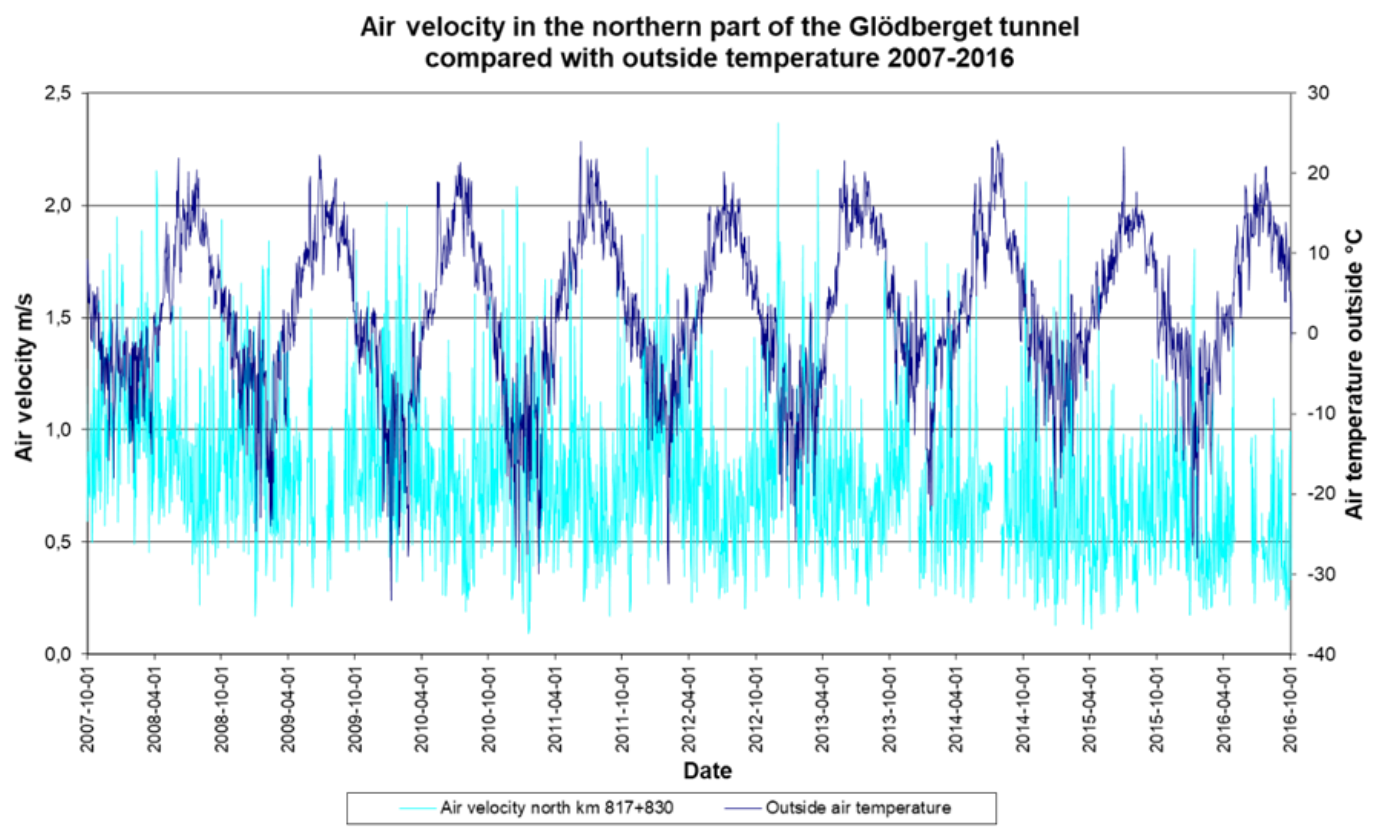

Figure 37: Air velocity in the northern part of the Glödberget tunnel, compared with outside temperature, 2007-2016.

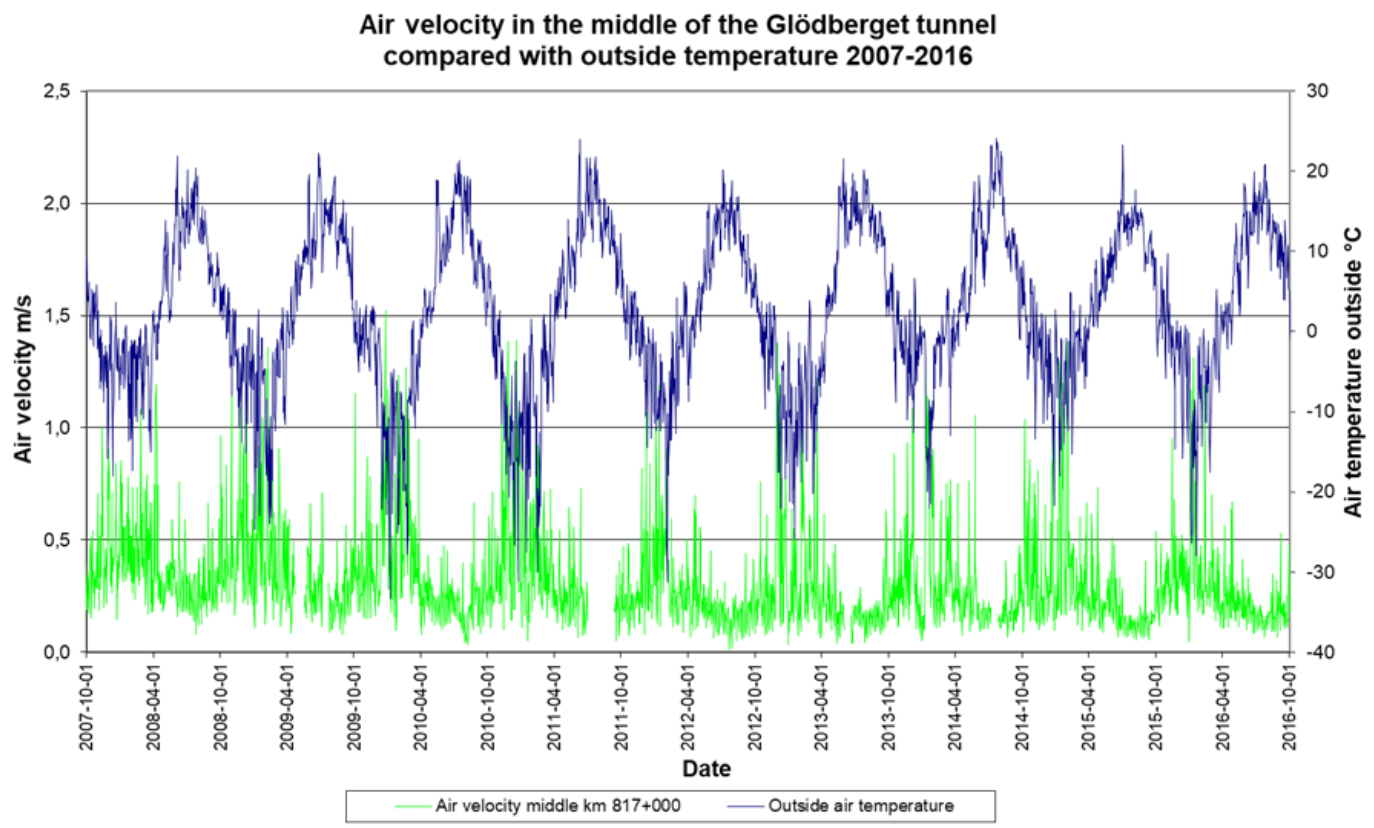

Figure 38: Air velocity in the middle of the Glödberget tunnel, compared with outside temperature, 2007-2016. 


\subsection{Wind direction outside the tunnels}

Figure 39 shows the dominant wind directions at the Åsa tunnel. The dominant wind direction is $210^{\circ}-230^{\circ}$ (from southwest) and partly $60^{\circ}-80^{\circ}$ (from northeast). The chart also shows the direction of the tunnel. The tunnel entrances are oriented $150^{\circ}$ and $330^{\circ}$ from the north. Since the dominant wind direction does not coincide with the direction of the tunnel entrances, it can be assumed that the outside wind does not affect the air movements in the tunnel to a large extent. This is confirmed by Figure 34 where the southern and northern measuring stations are slightly affected by the outside wind velocity (peaks following each other) but the air velocity in the tunnel is not of the same magnitude as the outside wind velocity.

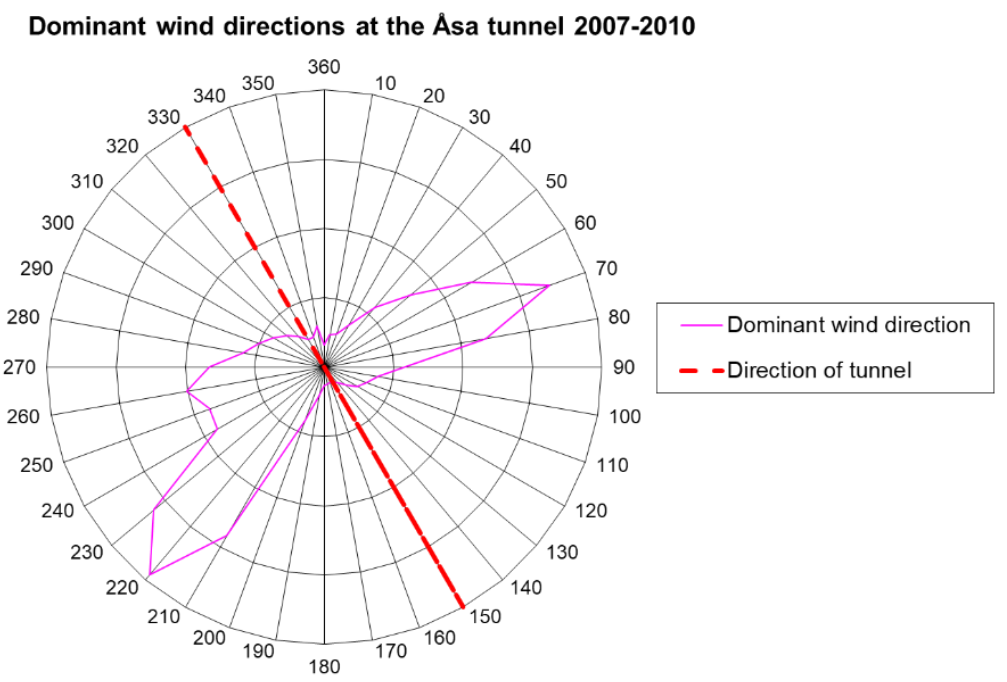

Figure 39: Dominant wind directions at the Åsa tunnel 2007-2010.

Figure 40 shows the dominant wind directions at the Glödberget tunnel and the tunnel direction. The dominant wind directions are $160^{\circ}-180^{\circ}$ (from southeast) and $280^{\circ}-320^{\circ}$ (northwest). The tunnel entrances have an orientation of $40^{\circ}$ and $220^{\circ}$ from north. Since the dominant wind direction differs from that of the tunnel entrances, the outside wind does not significantly affect the air movements in the tunnel. In the few occasions when the wind direction coincides with the direction of one of the tunnel entrances, a small increase in air velocity at the measuring station nearest the entrance can be detected. However, it does not give any impact along most parts of the tunnel, as seen in Figure 35. 
Dominant wind directions at the Glödberget tunnel 2007-2010

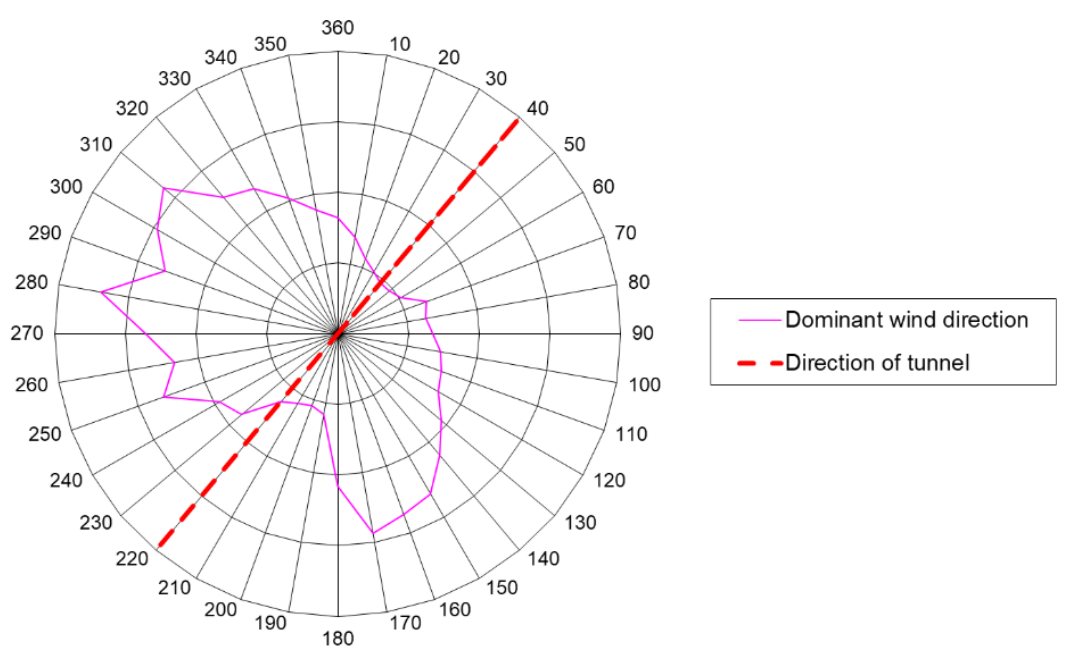

Figure 40: Dominant wind directions at the Glödberget tunnel 2007-2010.

\section{Conclusions}

The conclusions from this study are:

- Previous ideas about frost penetration problems was that ice formation occurred only at the tunnel entrances and the parts of the tunnel closest to the tunnel entrances. This field study has shown that the frost penetrates further into the tunnels than previously expected. In many cases, frost penetration occurs throughout the whole tunnel, even at a few degrees below zero outside the tunnel.

- For an inclined tunnel, the inclination and difference in the outside and tunnel air temperature is crucial for the length of frost penetration. Frost penetration occurs at a larger distance from the lower tunnel entrance than from the upper entrance, because the warm air, heated by the rock mass, moves due to the chimney effect towards the higher parts of the tunnel.

- If a tunnel has many frost-insulated drains installed, the heat transfer from the rock mass into the cold tunnel air is prevented by the insulation. Therefore, the cold outside air will be able to penetrate further into the tunnel and hence the frost problems in the inner parts will increase. Ice problems occur not only around the entrances but also often along the entire length of the tunnel. In early winter, the ice problems are most apparent close to the entrances, and tend to move inward the tunnel as winter goes on. When the rock mass has finally frozen, water in the fractures freeze and stop further water leakage into the tunnel.

- The air velocity at the stations closest to the tunnel entrances oscillates around 1 $\mathrm{m} / \mathrm{s}$ regardless of the time of the year or wind velocity outside the tunnel, unlike the air velocity in the middle of the tunnels, which increased during the winter periods. This indicates increased air flow throughout the entire length of the tunnel during the winter periods, resulting in increased frost penetration along the tunnel. 
- The frost does not penetrate so deep into the ballast bed as the recommended frost-proof depth in the year 1995 applicable regulations. Therefore, the blasting depth could be reduced and the drainage pipes in the middle parts of the tunnel could be placed shallower, but only if the drainage possibilities allow this.

- Temperature measurements behind a frost-insulated drain mat in the middle of the track tunnel in Glödberget showed that the selected drains are able to smooth out the temperature changes of the tunnel air. But when the temperature is sub-zero for a longer period, the temperature behind the drain drops below zero degrees. Then the water from the rock mass cannot be drained properly and frost shattering can occur. Water can begin to leak at the side of the drain, with formation of ice pillars and icicles as a result. However, the measurement was only made in the middle of the tunnel where the tunnel air is warmer than at the tunnel entrances. At the sections closer to the tunnel entrances, the temperature is colder and freezing behind the drain mats can occur. This indicates that the thickness and width of the drain mat is not sufficient for the cold temperatures of this region.

- Measurement in the adjacent service tunnel shows how great influence the air flow in the track tunnel has on the frost penetration. With closed doors at each service tunnel entrance, the air flow is constrained. The air is heated by heat exchange between rock and air and the tunnel air adopts the same temperature as the surrounding rock mass, which usually coincides with the annual average temperature applicable to the region where the tunnel is located.

- The influence of the outside wind velocity could not be properly investigated in this field study, because the dominant wind direction did not coincide with the direction of the tunnel entrances. When the wind direction coincided with the direction of one of the tunnel entrances, a small increase in air velocity at the measuring station nearest the entrance could be detected. However, it did not give any impact throughout the entire tunnel.

ACKNOWLEDGEMENTS: Thanks to The Swedish Transport Administration, Formas and BeFo for supporting this study. We would also like to thank the persons in the reference group: Tommy Ellison/Besab, Johan Funehag/LTU-Tyréns, Thomas Dalmalm/The Swedish Transport Administration and Per Tengborg/BeFo. 


\section{References}

[1] Andrén, A. (2009). Degradation of rock and shotcrete due to ice pressure and frost shattering. Luleå: Luleå University of Technology. Licentiate thesis. ISSN 1402-1757.

[2] Andrén, A. (2008). Analysis of tunnels with water and frost problems (In Swedish). The Swedish National Rail Administration: F07-15445/BA45, 2008-01-30.

[3] Sandberg, M., Claesson, L. and Blomqvist, C. (2002). Frost penetration in railway tunnels. Development of a design tool (In Swedish). Gävle: University of Gävle and the Royal Institute of Technology, Stockholm, and the Swedish National Rail Administration.

[4] Andrén, A. and Dahlström, LO. (2011). Temperature flows in railway tunnels - Glödberget tunnel (In Swedish). Luleå: The Swedish Transport Administration and Luleå University of Technology, 2011, Technical Report. ISBN 978-91-7439-318-7.

[5] Svensk, Byggtjänst (2017). RA Anläggning 17 - Råd och anvisningar till AMA Anläggning 17 (In Swedish). ISBN 978 91-7333-821-9.

[6] Andrén, A. (2008-2016). Temperature flows in railway tunnels Åsatunneln/Glödbergstunneln Status Report (In Swedish). The Swedish National Rail Administration and the Swedish Transport Administration: Åsatunneln F08-14245/BA45, Glödberget S05-3128/AL50.

[7] French, H.M. (1996). The periglacial environment. 2. ed. Harlow: Longman. ISBN 0-582-30536-5.

[8] Matsuoka, N. (2001). Microgelivation versus macrogelivation: towards bridging the gap between laboratory and field frost weathering. Permafrost and Periglacial Processes 12, 299-313.

[9] Dahlström, LO. (1992). Rock mechanical consequences of refrigeration - a study based on a pilot scale rock cavern. Ph.D. thesis. Chalmers University of Technology, Gothenburg. ISBN 91-7032-733-5.

[10] SMHI - the Swedish Meteorological and Hydrological Institute. http://www.smhi.se/ 